\title{
Self-Assembled Materials for Catalysis
}

\author{
Kake Zhu, Donghai Wang, and Jun Liu $(\bowtie)$ \\ Pacific Northwest National Laboratory, Richland, Washington WA 99252, USA \\ Received: 29 September 2008 / Revised: 6 November 2008 / Accepted: 8 November 2008 \\ (C)Tsinghua University Press and Springer-Verlag 2009. This article is published with open access at Springerlink.com
}

\begin{abstract}
The purpose of this review is to highlight developments in self-assembled nanostructured materials (i.e., mesoporous and nanoparticle-based materials) and their catalytic applications. Since there are many available reviews of metal-based nanoparticles as catalysts, this review will mainly focus on self-assembled oxide-based catalytic materials. The content includes: (1) design and synthetic strategies for self-assembled mesoporous catalysts, (2) polyoxometalate (POM)-based nanocatalysts, (3) dendrimer-based nanocatalysts, and (4) shaped nanomaterials and catalytic applications. We show that controlled assembly of molecules, crystalline seeds, and nano building blocks into organized mesoscopic structures or controlled morphologies is an effective approach for tailoring porosities of heterogeneous catalysts and controlling their catalytic activities.
\end{abstract}

\section{KEYWORDS}

Self-assembly, mesoporous, microporous, nanoparticles, polyoxometalates, dendrimers, zeolites, layered double hydroxides, heterogeneous catalysis

\section{Introduction}

Catalysis, in particular heterogeneous catalysis, plays a critical role in the world's economy and chemical industry. It is estimated that around $90 \%$ of chemical products of our current commercial processes are derived from heterogeneous catalytic processes [1]. Besides applications in the production of fine chemicals, catalysts also have extensive applications in the pharmaceutical, automobile, and food industries. The limited supply of non-renewable fossil energy sources (petroleum, coal, natural gas, etc.) and the environmental consequences of global warming both present new challenges in catalyst development. The design of novel catalysts is the key to most of the feasible processes for production of alternative fuels (such as the hydrogen or methanol economy) [2-4]. From the "Green Chemistry" point of view, it is also essential to develop new catalysts and alternative processes that reduce the use of precious metals and eliminate the utilization of toxic raw materials or production of harmful by-products [5].

Heterogeneous catalysts are widely investigated because of their high efficiency and reusability. Heterogeneous catalysis on solid surfaces occurs at active sites that catalyze a surface reaction by lowering the activation energy to a specific reaction pathway. The reaction pathway, in turn, determines the rate and the yield of the products which depend on the activity and selectivity of the catalyst. Moreover, to reach the catalytically active sites, the reactants need to diffuse through the boundary layer surrounding the solid catalyst before intra-particle diffusion and chemical adsorption. The products

Address correspondence to jun.liu@pnl.gov 
will also need to experience a reverse process to leave the catalyst after the reaction [6]. Therefore, surface structure/chemistry exerts kinetic control on the catalytic activity and selectivity. Tailoring the surface properties and structure of a catalyst support provides an effective way to design catalysts with the desired catalytic activity. Porosity, on the other hand, determines the mass transfer and heat transfer effects, and is crucial to diffusion controlled reactions. Tailoring the porosity of catalysts also provides a way to achieve shape-selectivity through either sieving reactants by their size, or restricting the structure of transition states/intermediates in order to produce selected products with controlled structures [7-11].

Most commercial catalysts are composed of a high surface area support on which active species are well dispersed, so that the number of active sites is maximized. These active species function in the form of small particles (normally in the nanometer size range). The catalytic activity and selectivity are dependent on the size, shape, and surface structure of the active species, as well as their composition. For instance, the activity of gold nanoparticles in $\mathrm{CO}$ oxidation is found to be highly sensitive to their size. Some studies have suggested that only those at nanometer scales are catalytically active, although the activity also depends on the reaction temperature and many other effects [12-14]. Single-site iron, copper, and titanium on mesoporous silica show high activity in catalyzing the oxidation of alkenes in the liquid phase [15-17]. Self-assembly has proven to be an effective way to produce both microporous/ mesoporous materials and nanoscale materials. These materials, when used as catalysts or supports, pave new roads for designing heterogeneous catalysts at the levels of both surface structure and porosity. These newly developed materials have shown impressive improvements in activity in comparison with traditional materials of the same composition. They also offer precisely controlled syntheses of model catalytic systems and enable a better understanding of surface structure-porosity-catalytic activity relationships.

Among high surface area catalysts, zeolites are widely used as both catalysts and supports, as well as in separation and purifications. Zeolites are a series of crystalline microporous $(<2 \mathrm{~nm}$, according to the IUPAC classification) solids which possess high internal surface area, unique surface chemistry, precise pore channels (less than $0.8 \mathrm{~nm}$ ) and cages (typically less than $1.5 \mathrm{~nm}$ ) close to the molecular scale, controlled framework structures, and tunable static electric fields inside the microporous channels. Zeolites provide high shape and size selectivity for guest molecules, and molecules activated by the internal electric field of zeolites will be more reactive than otherwise $[18,19]$. These merits together with their high thermal and hydrothermal stabilities make zeolites almost ideal supports for catalysts. However, their major drawback of small pore channels imposes diffusion limitations and causes high back pressures in flow systems [20-23]. In order to facilitate mass transportation, efforts have been made to increase the porosities of zeolite materials. In addition, mesoporous materials with pores ranging from 2 $\mathrm{nm}$ to $50 \mathrm{~nm}$ have been developed as substitutes for zeolites. Unlike porous solids, nanoparticles with surface functional groups do not suffer from such diffusion problems and are attractive candidates as heterogenous catalysts.

Recently, we briefly summarized the development of self-assembled materials for catalytic applications [24]. In this paper, we aim to present a much more complete and systematic review of this important field. In particular, we attempt to include some of the latest results published in the literature for self-assembled nanostructured materials (i.e., mesoporous and nanoparticle-based materials) and their catalytic applications. As there are already many reviews available for metal-based nanoparticles as catalysts [25-27], we will mainly focus on oxides and composite materials. Nano-sized metal oxides with controlled surfaces are also briefly highlighted, as tailoring surfaces provides another way to enhance catalytic activity and selectivity.

\section{Mesoscale design}

Self-assembly of cationic surfactants with an inorganic siliceous precursor to form a mesophase was first reported in a patent in 1971, but was not widely recognized due to the lack of structural 
information [28, 29]. From 1989 to 1993, Kato and co-workers developed an intercalation method to synthesize a series of ordered mesoporous silicas named folded sheet mesoporous materials (FSM) $[30,31]$ from the polysilicate kanemite. When a similar method was developed in 1992 by Mobil researchers (giving MCM-41, MCM-48, and MCM-50) and the structure was well resolved, great efforts were made to investigate the mechanism of formation and possible applications of the materials [32, 33]. MCM-41 shows a well-ordered hexagonal array of cylindrical pores with a relatively narrow pore size distribution. The pore walls are made up of amorphous silica. MCM-48 and MCM-50 are cubic and lamellar in their mesophase structure, respectively. Shortly after these earlier efforts, Stucky and Huo developed the surfactantinorganic precursor interaction method to extend the preparation to a variety of ionic surfactants. These interactions can be classified into $\mathrm{S}^{+} \mathrm{I}^{-}, \mathrm{SI}^{+}, \mathrm{S}^{+} \mathrm{XI}^{+}$, and $\mathrm{S} \mathrm{M}^{+} \mathrm{I}^{-}$pathways, ( $\mathrm{S}$ and I denote surfactant and inorganic precursor, respectively, while $\mathrm{X}^{-}$denotes anions such as $\mathrm{Cl}^{-}$or $\mathrm{Br}^{-}$, and $\mathrm{M}^{+}$denotes cations like $\mathrm{K}^{+}$or $\mathrm{Na}^{+}$), and can be used for the synthesis of not only siliceous materials displaying such mesophases, but also of non-siliceous mesoporous transition metal oxides and mixed oxides [34-36].

Pinnavaia's group were the first to use non-ionic templates to prepare mesoporous materials through $\mathrm{S}^{0} \mathrm{I}^{0}$ hydrogen bonding between polyethylene oxides (PEO) and inorganic species, which extended the synthesis to new polymer templates and larger pore sizes. The mesoporous silicas prepared using PEO have a less ordered wormhole-like structure. The pore size distributions of the materials are reasonably narrow and the pore walls are thick compared with the ionic surfactant templated mesoporous materials, and they are therefore more thermally stable [35, 37, 38]. Later in 1998, Stucky's group reported another series of mesoporous silicas (e.g., SBA-15 and SBA-16) prepared from tri-block co-polymers [39, 40]. SBA-15 and SBA-16 possess hexagonal $(P 6 \mathrm{~mm})$ and cubic phase $(\operatorname{Im} 3 m)$ structures respectively with a large pore size of above $6 \mathrm{~nm}$, and are more thermally stable compared with previously reported materials. More interestingly, there are interconnected micro-channels between the pores, thus forming a three-dimensional interconnected porous system. As far as the formation mechanism is concerned, the Mobil researchers first proposed a liquid crystal templating (LCT) model that suggests the formation of ordered hexagonal arrays results from cylindrical micelles formed with the mediation of charged silicate clusters. Polar groups of the surfactants in the cylindrical micelles stretch outwards, while the silicate precursor subsequently fills the spaces in between [32, 33]. Davis and co-workers, based on their in situ observations of the formation of mesophase silica, proposed that micelles form when positively charged surfactants attract several layers of negatively charged silicate species, followed by selfassembly into ordered structures by deposition of more inorganic layers [41]. The currently widely accepted mechanism, the charge density matching theory, was proposed by Stucky's group and involves selfassembly through a co-operative interaction between the organic templates and inorganic polyions during the hydrolysis of the precursors. Hydrolysis of the inorganic precursor changes the charge density at the interface between the inorganic clusters and the organic templates and tailors the subsequent mesophase which can range from hexagonal, cubic to lamellar in structure. Ordering of micelles before the formation of the inorganic walls is not necessary. The formation of the mesophase is thus controlled by the hydrolysis of the inorganic precursors, and the rate of hydrolysis is the rate determining step $[42,43]$. This mechanism is supported by in situ observations of mesophase formation and direct observations reported in later publications [42-45]. It should also be noted that the interaction between the inorganic precursors is also important in the cross-linking on the pore walls that controls the stability of the final porous solids during template removal by either combustion or extraction. An acid-base pair theory has been proposed as a guide to the synthesis of stable mesoporous mixed oxides [46].

Besides efforts to find new ways to tailor the structures and porosity of silica, applications of these materials in the field of heterogeneous catalysis are under intense investigation. Compared with zeolites, mesoporous silica possesses larger pore size facilitating mass transport, along with high surface

\section{Springer}


area. Silica materials are covered by weakly acidic silanol groups that are catalytically inert and have to be functionalized to be used as catalysts. Many methods have been employed to modify the surfaces of the pore channels. These methods can be divided into the following two major categories: postsynthesis modifications of mesoporous materials and in situ functionalized mesoporous materials [45, 47]. Herein we focus on the functionalized catalytic materials at the meso-scale obtained using the in situ self-assembly approach.

\section{1 Heteroatom inclusions}

\subsubsection{Acidic sites}

As acidic zeolite-based catalysts form a large category of heterogeneous catalysts and the small micropore size of zeolites limits larger molecules from approaching the active sites, this suggests the use of aluminated mesoporous silica to solve such a problem. Similar to the case in zeolites, substitution of tetra-coordinated silicon by a trivalent atom will create an acidic proton to compensate for the charge balance. $\mathrm{Al}^{3+}, \mathrm{B}^{3+}, \mathrm{Ga}^{3+}$, and $\mathrm{Fe}^{3+}$ have been extensively studied [48-55] as substitutes for tetracoordinated $\mathrm{Si}^{4+}$ in mesoporous silica. In the case of MCM-48 as support, the following ordering of acid strength is evidenced [54]: $\mathrm{Al}>\mathrm{Ga}>\mathrm{Fe}$. Two kinds of acid sites are observed for the substituted silica surfaces, Brønsted sites and Lewis sites, due to the coexistence of tetra-coordinated framework and extra-framework oxides, respectively. For instance, in a typical mesoporous aluminated silica, two peaks can be observed by ${ }^{27} \mathrm{Al}$ MAS NMR. The one close to $\delta=52 \mathrm{ppm}$ is from tetra-coordinated $\mathrm{Al}$ which gives rise to Brønsted sites, while the other one at $\delta=0$ ppm is from octahedral extra-framework Lewis sites. Washing with $\mathrm{NH}_{4} \mathrm{Cl}$ has been shown to remove some of the Lewis sites [48]. For Al-containing MCM-41, it is also evident that calcination leads to exclusion of aluminum from the framework and consequently causes loss of strong acid sites. The acidity of the sites becomes much weaker compared with such sites in zeolites, as a result of the noncrystalline nature of the pore walls [56]. When AlSBA-15 is directly synthesized, it is found to be more chemically and thermally stable than MCM-41 [57].
As far as catalytic applications are concerned, the acid sites in modified mesoporous silica are more active than zeolites for typical Brønsted acidcatalyzed reactions, especially for reactions of larger molecules. For instance, cumene cracking is found to be much easier using Al-SBA-15 as a catalyst than Al-MCM-41. This can be attributed to the existence of larger pores and interconnected small pores in SBA-15, which facilitate the mass transfer and therefore promote both conversion and selectivity [4854]. For Al-, Ga-, and Fe- substituted MCM-48 used as catalyst for acetone conversion, the majority of active sites are weak to medium acid sites, while a minority of strong acid sites co-exist, which may be the reason for the observed low selectivity [52]. In addition to in situ and post-synthetic grafting methods for the introduction of $\mathrm{Al}$ into the matrix of mesoporous silica, supercritical fluids $\left(\mathrm{CO}_{2}\right.$ or propane) have also been employed to enhance the interaction between $\mathrm{Al}$ and silica walls inside the channels since this leads to a highly thermally and hydrothermally stable AlMCM-41 material [55]. The strength of acidity and the stability of these materials remain problematic however, and the use of supercritical fluids is expensive and requires high pressures.

Attempts have also made to prepare frameworks of crystalline pore walls or semi-crystalline pore walls in order to combine the merits of zeolites and mesoporous structures in one material $[47,58]$. The Kaliaguine group used SBA-15 and a ZSM-5 gel synthesized in house as the starting materials, and recrystallized the resulting composite in glycerol to prepare such a composite material [58]. The use of dual templates for the synthesis of zeolite and mesoporous silica has also been studied by several groups. However, there is no direct evidence for homogeneity in these composites [58, 59], and indeed there is evidence that these materials may be composed of mixtures of both mesoporous and zeolitic components [20]. Creating additional porosity in zeolitic crystals is an alternative way to circumvent diffusion difficulties, and has been studied by several groups $[20,60]$. This type of zeolite, containing both micropores from zeolitic structures and additional porosity of meso-scale or larger, is thereby a hierarchical porous material and 
has high thermal and hydrothermal stabilities. The very first hierarchical porous silicalite-1 was prepared by Jacobsen and co-workers. Their process used a nanoscale carbon black powder as a hard template to crystallize silicalite- 1 gel through vapor phase transportation. Subsequent combustion of the carbon black and organic template produced a mesoporous silicalite-1 [60]. X-ray diffraction (XRD) patterns confirmed a phase-pure MFI structure for the hierarchical porous silicalite-1. Nitrogen adsorptiondesorption isotherms showed an $\mathrm{H} 1$ hysteresis loop in a type IV isotherm which is characteristic of large mesopores. Scanning electron microscopy (SEM) images showed coffin-like and sponge-like discrete crystals with typical MFI shapes [61]. Other types of hard templates have also been used to prepare zeolites with similar structures, including carbon aerogels, mesoporous carbon, and polymers [20]. The high expense and low efficiency of the hard template approaches still remain a concern for large scale synthesis however. For example, only $25 \%$ of the carbon black actually creates pores in the hierarchical porous silicalite-1, while the remainder does not contribute to the mesoporosity.

Some successful attempts based on self-assembly approaches using polymers as co-template [62] or silanes [63] as silica source have been developed, which produce materials with both crystalline zeolite morphologies and mesoporosities. Figure 1 shows the morphologies of mesoporous $\beta$-zeolite obtained by a co-template method. BEA- and MFI-type zeolites have been prepared by using cationic polymers as templates; these can interact with negatively charged silica sources during the synthesis and facilitate the growth of zeolitic seeds. Transmission electron microscopy (TEM) images show uniform crystalline particles of around $600 \mathrm{~nm}$ with the interconnected mesopores open to the surface, confirming that the material is phase-pure and hierarchically porous. The mesoporous zeolite is highly crystalline and has been used as a catalyst for the alkylation of benzene with propan-2-ol. The improved activity and selectivity for the desired products, as compared with conventional $\beta$-zeolites, indicates the importance of hierarchical porosity for mass transportation during catalytic reactions (Fig. 2) [62].
Ryoo's group developed another method to synthesize mesoporous aluminated zeolites with MFI and LTA structures by using a silane-based surfactant [3-(trimethoxysilyl)propyl]hexadecyl dimethyl-

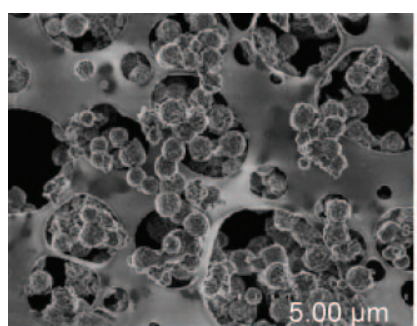

(a)



(c)

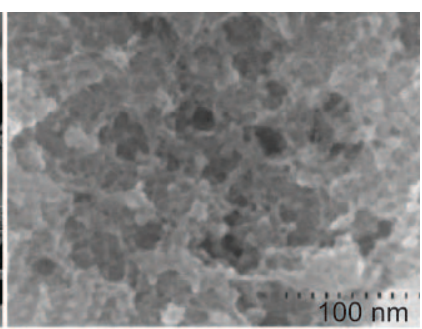

(b)
Figure 1 SEM and TEM images of hierarchical mesoporous $\beta$-zeolite obtained by co-templating with tetraethylammonium hydroxide and polydiallyldimethylammonium chloride. The material is highly crystalline as evidenced by HRTEM as shown in (d) [62] (Copyright Wiley-VCH Verlag GmbH \& Co. KGaA, Weinheim. Reproduced with permission)

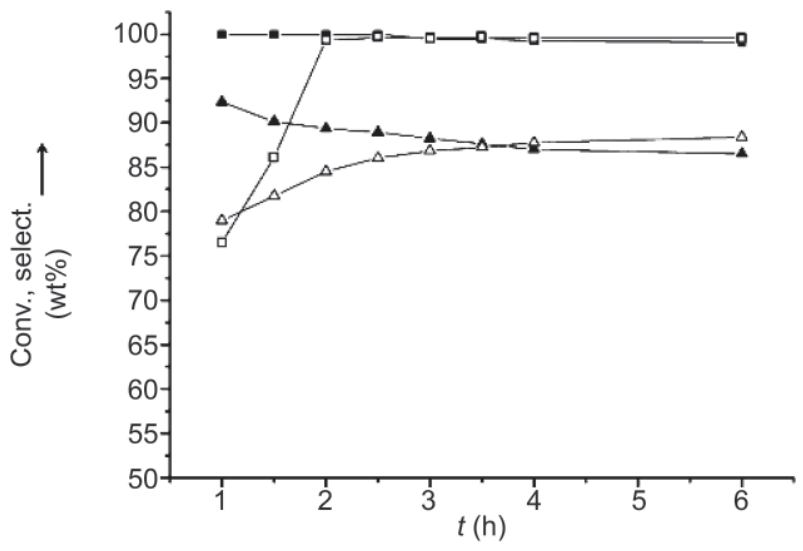

Figure 2 Catalytic conversions (conv. [wt \%]) and selectivities (select. (wt \%)) in the alkylation of benzene with propan-2-ol with various zeolite samples as a function of reaction time (reaction temperature: $200{ }^{\circ} \mathrm{C}$; 4:1 benzene/propan-2-ol; reaction pressure: $2.0 \mathrm{MPa}$ ). Conversion over $\beta-\mathrm{H}$ (solid squares); selectivity over $\beta-\mathrm{H}$ (hollow squares); conversion over $\beta$-zeolite (solid triangles); selectivity over $\beta$ zeolite (hollow triangles) [62]. (Copyright Wiley-VCH Verlag GmbH \& Co. KGaA, Weinheim. Reproduced with permission) 
ammonium chloride. From SEM and TEM images, mesopores could be identified (Fig. 3). The catalytic syntheses of vesidryl and jasminaldehyde using the acidic sites in the MFI structure were compared with their non-crystalline counterpart and conventional zeolites. These results are shown in Table 1 [63]. For large molecular substrates, the catalytic activity for the mesoporous zeolites is significantly higher than for conventional zeolites. The pore size limitation of conventional zeolites becomes more obvious for larger molecules, since catalytic conversion of the reactants occurs only on the external surfaces, while for mesoporous zeolites catalysis happens on both external surfaces and inside the mesopores [63]. Similarly, mesoporous H-ZSM-5 also shows improved activity and selectivity in the catalytic alkylation of benzene to ethylbenzene, due to its highly crystalline pore walls and hierarchical porosity that make the acid sites stronger and mass transportation easier, as evidenced by ${ }^{27} \mathrm{Al}$ MAS NMR and ammonia temperature programmed desorption (TPD) measurements [64]. Although these developments show that creation of additional pores in zeolites is important in heterogeneous catalysis, as the enhanced activity and longer life span of the catalyst have economic benefits, the current methods are still too expensive for commercial applications, however. Finding inexpensive precursors and new templates, as well as extension of these methods to other types of zeolites are important directions for further development. From the point of view of

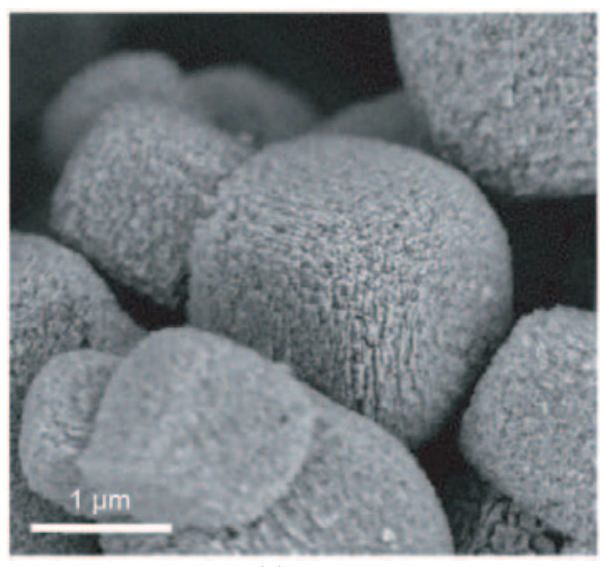

(a)

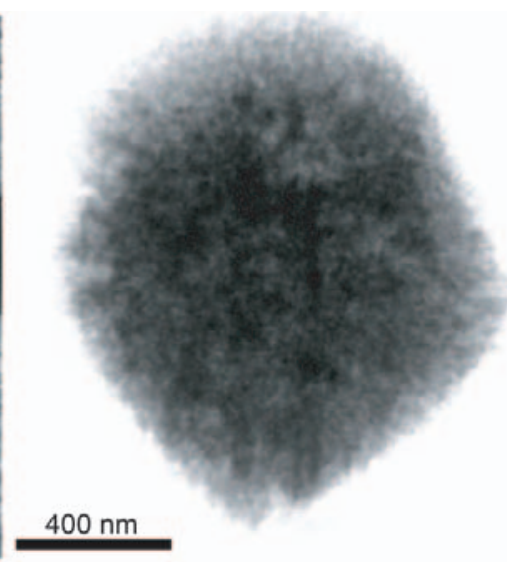

(b)
Figure 3 SEM and TEM images of crystalline zeolite having mesoporosity obtained using [3-(trimethoxysilyl)propyl]hexadecyldimethylammonium chloride $\left(\left[\left(\mathrm{CH}_{3} \mathrm{O}\right)_{3} \mathrm{SiC}_{3} \mathrm{H}_{6} \mathrm{~N}\left(\mathrm{CH}_{3}\right)_{2} \mathrm{C}_{16} \mathrm{H}_{33}\right] \mathrm{Cl}\right.$, TPHAC) [63] (Copyright Nature Publishing Group. Reproduced with permission) catalysis, most of these materials have, so far, mainly been used as acidic catalysts. The possibilities of extending the catalytic applications to other types of reactions and supported materials have not been widely investigated.

\subsubsection{Highly dispersed metal oxides}

Besides the use of trivalent metals to create acidic sites, other transition metals have also been incorporated into mesoporous silica through selfassembly of metal alkoxides or salts together with siliceous sources. When combined with the high surface area of the mesoporous supports, transition metal substituted mesoporous silicas show many improvements in heterogeneous catalysis [45, 47]. In Ti-MCM-41 and Ti-HMS, there are abundant tetra-coordinated $\mathrm{Ti}$ sites on the surface of mesochannels that show superior activity in catalytic oxidation reactions. In the catalytic oxidation of 2,6-di-tert-butyl phenol to the corresponding quinone Pinnavaia and co-workers reported a conversion of $83 \%$ using Ti-HMS, as compared to $6.5 \%$ for conventional TS-1, without sacrificing selectivity ( $>95 \% \$ 154.86$ in both cases) [65]. This extraordinary result was attributed by the authors to site-isolation of the majority of the active sites, predominance of tetra-coordinated titanium species, and titanium siting that was virtually independent of the framework assembly pathway [66]. However, Corma and co-workers found that the intrinsic catalytic activity was not as high when compared to the zeolitic counterpart TS-1. For large molecular substrates, mesoporous Ti-containing materials are more catalytically active, due to the adverse effects of the microporosity of the zeolites on mass transportation during reactions [67]. Moreover, because the $\mathrm{Ti}-\mathrm{O}$ bond length is longer than the $\mathrm{Si}-\mathrm{O}$ bond length, the Ti content in Ti-containing mesoporous silica can vary over a large range, while in TS- 1 the $\mathrm{Ti}$ inside the crystalline framework is normally $[68,69]$ less than $2 \mathrm{wt} \%$. 
Other transition metal substituted mesoporous materials show similar improved catalytic properties by virtue of enhanced mass transport of large molecular reactants. When tungsten substituted mesoporous silica is used as a catalyst for the selective oxidation of cyclopentene to glutaraldehyde in tert-butanol as solvent [70,71], high selectivity and high conversion (85\%) is achieved at a high $\mathrm{H}_{2} \mathrm{O}_{2}$ efficiency $(60 \%-77 \%)$. In the case of vanadium containing mesoporous silica prepared by direct synthesis, at low vanadium contents ${ }^{51} \mathrm{~V}$ NMR and Raman spectroscopy indicate that most of the vanadium species are highly dispersed and no large aggregates are present. The V-containing mesoporous silica also exhibits high activity in liquid phase $\mathrm{H}_{2} \mathrm{O}_{2}$ oxidation of large molecules, such as cyclododecane and 1-naphthol [72, 73].

Substitution of hetero-atoms into the mesoporous silica walls as a way to prepare heterogeneous catalysts possesses the merits of simplicity in preparation, and gives high dispersion and versatility in structure control, but problems exist such as low loadings, low thermal/hydrothermal stability, lack of precise control over active sites, unavailability of deeply embedded atoms to substrates, and leaching during reactions. Therefore it is desirable to develop methods to control the surface structures more precisely and to enhance the stability of these systems.

\subsection{Embedded nanoparticles}

Although nanoscale metals have been used in heterogeneous catalysis for a long time, current methods do not provide precise control over catalyst sizes [74]. As nanoscale particles have high surface area, high surface to bulk atomic ratio (unsaturated surface atoms are more active), their size-dependent, and support effects are different from their bulk counterparts. These features make nanoparticles attractive for catalysis. Combination of nanoparticles with mesoporous materials through self-assembly methods provides a new way for catalyst design. Through the self-assembly approach, nanoparticles can be well dispersed within a high surface area support and the final material is no longer susceptible to sintering. Two categories of precursors can be used in studying catalysis by metal oxide nanoparticles: either molecules or nanoparticles. For instance, iron ethoxide can be used as a precursor to form iron oxide nanoparticles embedded in the aluminosilicate walls through self-assembly of co-polymer and inorganic sources [75], and titanium isopropoxide can be used to synthesize anatase nanoparticles embedded in mesoporous silica [76]. Alternatively, preformed nanoparticles of $\mathrm{CeO}_{2}$ have been selfassembled with tetraethyl orthosilicate (TEOS) by using poly(alkyleneoxide) block copolymers as a template in acidic media. A highly ordered hexagonal structured composite material is produced after calcination of the organic templates. Discrete highly crystalline $\mathrm{CeO}_{2}$ nanoparticles are embedded in the silica walls and are stable up to $800{ }^{\circ} \mathrm{C}$, due to the protection afforded by the thick pore walls. Such a composite material itself, or after doping with vanadium, shows high activity in sulfur removal during gasoline cracking [77]. This precursor concept is interesting as it demonstrates the possibility of preparing a composite from nanoparticles and molecules through a single step self-assembly. However, the method used to prepare the $\mathrm{CeO}_{2}$ nanoparticles and the subsequent purification are rather complex.

In order to embed metallic nanoparticles into the inorganic walls, it is convenient to employ chelating reagents that build linkages between the metal ions and the inorganic walls. For example, with the help of bis[3-(triethoxysilyl)propyl]tetrasulfide, $\mathrm{HAuCl}_{4}$ can be co-precipitated with TEOS during its hydrolysis, and be included into the silica walls of mesoporous silica SBA-15 [78]. Figure 4 shows a scheme of the preparation procedure. Au ions are inserted into the silica matrix and subsequently converted to metallic $\mathrm{Au}$ after removal of the surfactant upon calcination. The ultrafine $\mathrm{Au}$ nanoparticles show improved thermal stability within the silica framework. After calcination at $500{ }^{\circ} \mathrm{C}$, the particle size is around 3 $\mathrm{nm}$ for a $1.5 \mathrm{wt} \%$ loading, which is the optimum size for catalytic activity [13]. The conventional loading method to confine gold nanoparticles within mesopores cannot produce stable particles of around $2-3 \mathrm{~nm}$ because $\mathrm{Au}$ is found to be highly mobile on silica surfaces as a result of the weakly 




Figure 4 Graphical representation of the preparation process for mesoporous silica catalysts with gold nanoparticles in the walls [78] (Copyright Elsevier, Inc. Reproduced with permission.)

acidic nature of the surface (low isoelectric point), and it is hard to immobilize the nanoparticles and prevent aggregation under reaction conditions [79, 80]. The embedded Au nanoparticles are available to substrates because of the interconnected micropores created by calcination of the polymer templates. The catalysts are found to have high activity (TOF = 377) for the aerobic oxidation of benzyl alcohol and cyclohexanol. No growth of particle size is observed after 3 catalytic cycles.

Another example is Pt embedded SBA-15 recently reported by the Yang and Somorjai groups [81]. The authors firstly prepared a Pt colloid of controlled size $(1.7-7.1 \mathrm{~nm})$ with the assistance of poly(vinylpyrrolidone). The Pt nanoparticles were then dispersed in a synthetic gel of SBA-15 at neutral $\mathrm{pH}$ with $\mathrm{NaF}$ used to mineralize the siliceous source. During the preparation, the $\mathrm{pH}$ was adjusted to neutral to match the colloid stability with that of the mesophase micelles. Ethylene hydrogenation and ethane hydrogenolysis activity of the resulting catalyst were tested. The former was insensitive to particle size, while the latter was found to be favored by decreasing particle size. This was attributed to the roughness of the surfaces for smaller particles, as shown by their active surface area for $\mathrm{CO}$ adsorption [81]. In inclusion chemistry of nanoparticles in silica walls, SBA-15 is preferred because of the thick walls (3-4 nm) between the channels and its thermal stability. The synthesis of embedded metallic particles is challenging, as there are many factors to be considered: stability of the particles, $\mathrm{pH}$ range for self-assembly, the need for the particle size to be smaller than the pore wall thickness, and the stability during template removal.

\subsection{Non-siliceous mesoporous materials}

Synthesis and applications of non-siliceous metal oxides in catalysis have attracted much attention [45, 82]. Mesoporous transition metal oxides are attractive heterogeneous catalysts or catalyst supports compared with the bulk oxides because they possess high surface area and expose large numbers of active sites or defects. In terms of mass transportation, their large pores are superior to microporous materials. Despite the lack of crystallinity and cross-linking between the metal oxide walls that makes them less stable to collapse after template removal by combustion [83], there are some successful examples of applications in catalysis. For clarity, we divide these examples into two parts with respect to the inorganic sources: molecule self-assembly and nanoparticle self-assembly.

\subsubsection{Self-assembly of precursor molecules}

Metal alkoxides or chlorides are normally used as 
sources for self-assembly with organic surfactants, including both ionic and non-ionic surfactants, to synthesize mesoporous oxide catalysts. One successful example of a thermally stable mesoporous non-siliceous material is $\gamma$-alumina. Yan and coworkers used the triblock co-polymer pluronic P123 $\left(\mathrm{EO}_{20} \mathrm{PO}_{70} \mathrm{EO}_{20}\right)$ as template to prepare mesoporous alumina through solvent evaporation induced selfassembly in ethanol solution [84]. XRD and TEM images confirmed that the structure is a highly ordered hexagonal mesophase. Wide angle XRD as well as ${ }^{27} \mathrm{Al}$ MAS NMR suggested that the pore walls are a crystalline $\gamma$-phase after calcination at $900{ }^{\circ} \mathrm{C}$. Pyridine adsorption infrared spectroscopy showed that the surfaces have abundant Lewis acid sites. When loaded with ruthenium as a catalyst for the hydrogenation of glucose, acetone, and cellobiose, the material showed shape-selectivity as a result of steric hindrance.

To prepare a $\mathrm{V}-\mathrm{TiO}_{2}$ catalyst with a BET surface area greater than $1000 \mathrm{~m}^{2} / \mathrm{g}$, Yoshitake and coworkers [85] synthesized mesoporous mixed oxides by using dodecylamine as template and vanadium oxytriisopropoxide and titanium tetraisopropoxide as metal sources. Interestingly, the directly prepared catalyst has $\mathrm{V}^{4+}$ as the dominant species on the surface, while the post-synthesized material has $\mathrm{V}^{5+}$ as the dominant species. The directly synthesized $\mathrm{V}-\mathrm{TiO}_{2}$ catalyzes propylene oxidation with a higher selectivity towards $\mathrm{CO}_{2}$ than the post-synthesized materials. Kapoor and co-workers [86] studied the production of hydrogen through methanol decomposition over ultrafine $\mathrm{Pd}$ supported on mesoporous $\mathrm{TiO}_{2}$, which showed better catalytic activity than commercial products. The high catalytic activities were attributed to the improved dispersion of ultrafine $\mathrm{Pd}$ particles in the meso-channels, which may be a result of nano-channel confinement. Serre's group [87] reported the preparation of thermally stable cubic and hexagonal mesoporous tin phosphates using $\mathrm{SnF}_{4}$ as metal source and cationic surfactants as templates. The materials exhibit catalytic activity in the deNO $\mathrm{N}_{x}$ reaction in the presence of ethane, a typical test for selective catalytic reduction of air pollutants. Ammonia adsorption indicates that the surfaces are strongly acidic, suggesting that these materials can also be used in acid catalyzed reactions.

Mesoporous titanium phosphate prepared in a similar way by using both cationic and anionic templates has been reported by researchers at Toyota. The inorganic matrix also possesses anion-exchange capabilities due to the presence of phosphonium cations in the framework, and cation-exchange capabilities as a result of the presence of $\mathrm{P}-\mathrm{OH}$ groups. When used to catalyze the oxidation of cyclohexene with hydrogen peroxide, it showed high activity and selectivity towards 1,2-cyclohexanediol because the tetra-coordinated $\mathrm{Ti}$ active sites for this reaction are predominantly on the surface [88]. This is important because it shows the possibility of tailoring porosity and surface chemistry simultaneously, i.e., the catalytic activity and selectivity can be rationalized in terms of the structures of the active sites.

Besides being used as catalysts, these mesoporous transition metal oxides also show improved catalytic behavior when used as supports. Mesoporous alumina as a support for $\mathrm{Ru}$ is superior in olefin metathesis to other types of alumina [89]. Mesoporous $\mathrm{ZrO}_{2}$ and $\mathrm{CeO}_{2}$ prepared using inorganic salts are stable catalyst supports. For instance, compared to non-porous supports, Pd supported on $\mathrm{ZrO}_{2}$ is better when used in phenol hydrogenation, as a result of the high dispersion of the metal [90]. Catalytic applications of mesoporous materials are not limited to oxides. Micro- and meso- porous silicon imido nitride obtained by an organic selfassembly method showed pore-size dependent selectivity for isomerization of alkenes or alkylation of alkylbenzenes [91].

The mesoporous materials obtained by molecule self-assembly have, nevertheless, non-crystalline pore wall structures, which limits their applications to low temperatures and relatively mild conditions. It is, therefore, desirable to develop mesoporous materials with crystalline walls. Titania with crystalline walls having the rutile polymorph has been synthesized by some of us, by using the anionic template sodium dodecylsulfate as structure directing agent and $\mathrm{TiCl}_{3}$ as inorganic precursor; these self-assemble into a well ordered mesophase with highly crystalline walls

\section{算 Springer}


[92]. When gold nanoparticles are loaded onto the support, the material shows superior catalytic activity towards $\mathrm{CO}$ oxidation at temperatures as low as -50 ${ }^{\circ} \mathrm{C}$ [93]. Figure 5 shows a scheme for the formation of mesoporous rutile titania and the corresponding TEM images; from the latter both the mesopores and crystallinity can be identified. Another strategy to synthesize mesoporous materials with crystalline walls is through self-assembly of crystalline nanoparticles into mesoporous crystalline materials with the assistance of templates. Syntheses of some of these materials are still quite time consuming and not easy to control. For instance, solvent evaporation induced self-assembly takes a long time and may not



(a)

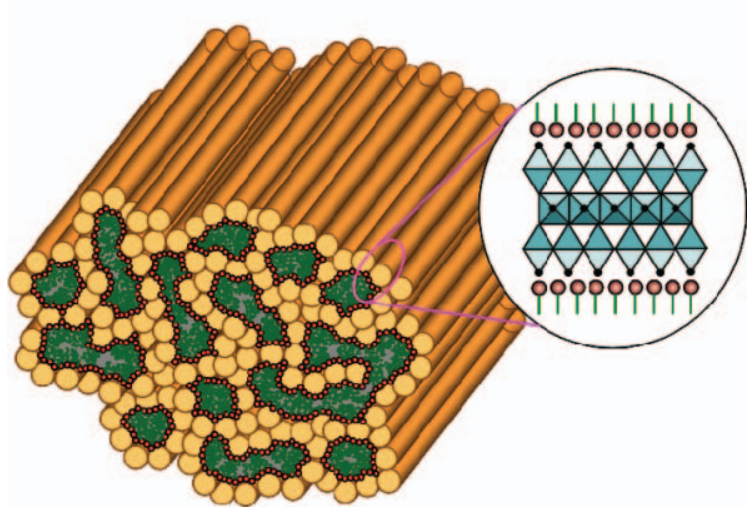

(b)

Figure 5 (a) TEM image of mesoporous crystalline rutile. The inset shows the selected area electron diffraction pattern of the crystalline rutile phase; (b) Schematic showing aligned rutile nanocrystals organized in a parallel fashion into mesoporous structures [92, 93] (Reproduced with permission) be easy to scale up; greater simplicity in synthesis is still desirable.

\subsubsection{Self-assembly of precursor nanoparticles in solution}

Early efforts to prepare mesophase materials from nanoscale building blocks started in Ying's group, who synthesized a tungstated zirconium oxide through the self-assembly of a co-polymer surfactant with a zirconium oxide colloidal sol and ammonium metatungstate. The composite material is thermally stable but not highly crystalline [94]. Corma's group subsequently developed a method to synthesize the mesoporous metal oxides $\mathrm{ZrO}_{2}$, $\mathrm{CeO}_{2}$, and $\mathrm{CeO}_{2}-\mathrm{Al}(\mathrm{OH})_{3}$ using $3 \mathrm{~nm} \mathrm{CeO}_{2}$, 5 $\mathrm{nm} \mathrm{ZrO}_{2}$, and $3 \mathrm{~nm} \mathrm{Al}(\mathrm{OH})_{3}$ colloids as starting materials, and co-polymers as templates. Figure 6 shows the XRD patterns at both low angle and high angle of mesoporous $\mathrm{CeO}_{2}$ together with the corresponding TEM images. The products show well-ordered mesoporous structures with crystalline frameworks. To create strong interactions between nanoparticles and surfactants and facilitate the selfassembly, small bi-functional molecules such as 6-aminocaproic acid are used. For example, $-\mathrm{COOH}$ groups in 6-aminocaproic acid will combine with $\mathrm{CeO}_{2}$ surface hydroxyl groups, while the amine interacts with the poly(alkyleneoxide) backbone of the surfactants. When employed as photo anodes in photoelectrochemical solar cells, the novel mesoporous crystalline $\mathrm{CeO}_{2}$ exhibits a photovoltaic response due to its high surface area semiconductor properties $[95,96]$. $\mathrm{CeO}_{2}$ is an oxygen conductor and therefore a suitable support for aerobic oxidation. When $\mathrm{Au}$ nanoparticles are loaded onto the support, the mesoporous $\mathrm{CeO}_{2}$ is able to catalyze the selective aerobic oxidation of aliphatic and aromatic aldehydes. It exhibits better activity and selectivity than other reported catalysts. Furthermore, the catalysts can be recycled, due to their stability under the reaction conditions [97]. Control of precursor particle size distribution is crucial in the synthesis, and composite materials prepared by this strategy are unique, as they are composed of mixed single nanoparticles of different oxides, which can provide a way to manipulate the spacing of active sites in 




(a)



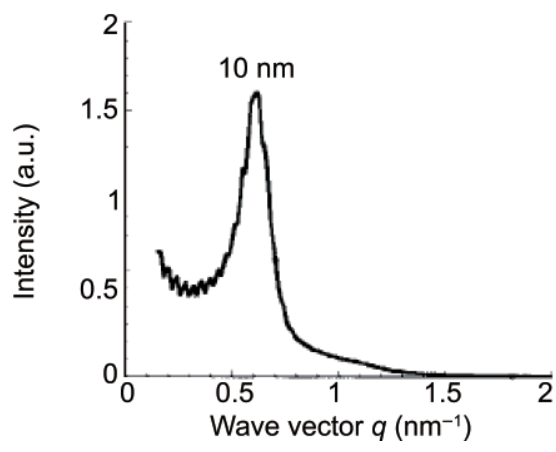

(b)

(c)

Figure 6 Low angle and wide angle XRD patterns, and TEM images of self-assembled $\mathrm{CeO}_{2}$ nanoparticles after calcination at $500{ }^{\circ} \mathrm{C}$ [95] (Copyright Wiley-VCH Verlag GmbH \& Co. KGaA, Weinheim. Reproduced with permission)

future catalysts or to prepare bi-functional catalysts.

\subsubsection{Self-assembly of nanoparticles in the confined interlayer space of layered materials}

The intercalation of cationic surfactants such as alkyltrimethylammonium chloride into layered materials to form mesoporous materials was first reported by Kato and co-workers using polysilicate kanemite as the host material [30,31]. This concept has subsequently been used to prepare mesoporous materials through the self-assembly of nanoparticles with layered materials [98-100]. Intercalation of clays to form new layered compounds has a long history, but most studies are based on the ion-exchange of metallic cations and therefore only microporous composites are produced [101-103]. Watanabe and co-workers found that tetrabutylammonium (TBA) cations can swell the layers of a protonic titanate and by controlling the TBA content, titanate sheet structures formed after exfoliation. A series of composite materials have been developed based on their findings [104-106]. Hata recently reported that $\mathrm{Rh}(\mathrm{OH})_{3}$ ultrafine nanoparticles can be deposited on a Dion-Jacobson type layered perovskite $\mathrm{ACa}_{2} \mathrm{Nb}_{3} \mathrm{O}_{10}(\mathrm{~A}=\mathrm{H}$ or $\mathrm{K})$ if the host is first exfoliated by TBA to form delaminated sheets, followed by $\mathrm{Rh}(\mathrm{OH})_{3}$ deposition, ion-exchange of TBA by K, and calcination. The composite shows activity for the evolution of hydrogen from a $10 \%$ methanol solution [106]. Kim et al. have described the insertion of positively charged nickel hydroxide nanoparticles into the negatively charged layered structure of a protonated titanate. The resulting mesoporous composite has a surface area of $190 \mathrm{~m}^{2} / \mathrm{g}$ with a pore size of 3.7 to $4 \mathrm{~nm}$. The composite catalyzes the epoxidation of cyclohexene with selectivity above $90 \%$ at an $\mathrm{H}_{2} \mathrm{O}_{2}$ efficiency over $80 \%$. Furthermore, the material is also catalytically active for the photocatalytic degradation of 4-chlorophenol under visible light irradiation ( $\lambda>420 \mathrm{~nm}$ ) [100]. Wang et al. found that Keggin type $\left[\mathrm{Al}_{13} \mathrm{O}_{4}(\mathrm{OH})_{24}\left(\mathrm{H}_{2} \mathrm{O}\right)_{12}\right]^{7+}$ clusters self-assemble with layered manganese oxide to produce an intercalated composite porous material, with a broad pore size distribution in the range 2 to 8 $\mathrm{nm}$. The resulting amorphous mesoporous composite material is stable up to $500{ }^{\circ} \mathrm{C}$ [99]. 
In the case of non-charged nanoparticles, it is impossible to intercalate them between charged layers, which makes it necessary to functionalize the nanoparticles before self-assembly with layered hosts. For instance, Au nanoparticles cannot enter the interlayer galleries of fluoromica or Dion-Jacobson phase layered perovskites directly. However, Au particles can interact with the free amine groups from poly(allylamine) pre-intercalated into layered host materials and self-assemble with the layered hosts to give layered composite compounds [107]. Control of $\mathrm{pH}$ is important in order to effectively attract $\mathrm{Au}$ nanoparticles because protonated amines are no longer active for gold immobilization. Thermal stability of materials during subsequent removal of organic templates by combustion is still a challenge restricting the applications of such materials in heterogeneous catalysis [106, 107]. The intercalated layers provide a platform for the tailoring of nanoscale structured materials, but the drawbacks of the preparation methods are that they are very time consuming, and the structure-activity relationships are not well understood.

\subsection{Self-assembly of zeolitic nanoseeds}

Employing nano-sized zeolite seeds to prepare zeolites with hierachical porous structures has attracted much attention after the failure to crystallize the walls of mesoporous materials through postsynthesis treatment. Pinnavaia and co-workers have used Y-zeolite seeds to prepare mesoporous AlMSU-S. When cumene cracking is used as a probe catalytic reaction, improved activity is achieved using Al-MSU-S with respect to conventional AlMCM-41. ${ }^{27} \mathrm{Al}$ MAS NMR spectroscopy shows that the $\mathrm{Al}$ chemical shift in Al-MSU-S is close to that in zeolitic structures and steaming stability is therefore enhanced. Above $800{ }^{\circ} \mathrm{C}$, however, the thermal stability decreases although this is due to carbon formation rather than low framework stability [108]. When ZSM-5 or $\beta$-zeolite seeds are employed as a starting material, the resulting mesoporous materials are found to be intrinsically stable and do not require the presence of occluded carbon to confer steam stability [109]. Xiao and co-workers reported similar methods using zeolite clusters as starting materials which self-assemble into a mesoporous BEA-structure. Catalytic activity in the alkylation of isobutene by 2-butene and in 1,3,5-triisopropylbenzene cracking were compared with zeolites and mesoporous counterparts. The improvement in catalytic activity for the mesoporous zeolitic materials is dramatic when compared with conventional AlMCM-41. Furthermore, in the catalytic alkylkation reaction, the activities of HZSM- 5 and Al-MCM-41 decay after 10 and $17 \mathrm{~h}$, respectively, while the mesoporous zeolitic material shows little deactivation during the whole test period of $20 \mathrm{~h}$ [110]. Most of these materials do not show the characteristic XRD patterns of zeolites, probably as a result of the very small crystallite size, and therefore further characterization and mechanistic studies are necessary to increase our understanding of these systems.

\subsection{Self-assembly of functional organic molecules on pore walls}

Organic functionalization of ordered mesoporous materials has attacted great interest for heterogeneous catalysis by virtue of the ability either to immobilize metal ion centers through chelating or anchoring, or to form metal-free organocatalysts directly. Functionalization on the surface of mesoporous silica is completed by either post-synthetic grafting of organosilanes or direct in situ synthesis of mesoporous silica with addition of appropriate functional precursors [45, 47, 110, 111]. For example, 3-aminopropyltrialkoxysilane has been used as a precursor to add amine groups onto the surface, and 3-mercaptopropyltrialkoxysilane provides the means to modify silica surfaces with thiol functional groups. The Davis group designed a catalyst based on mesoporous silica with discrete pairs of sulfonic acid and thiol groups for condensation of acetone and phenols. The bi-functional catalyst was found to be three time more active than one with randomly distributed active sites [112]. Careful control of the synthetic procedure and appropriate choice of precursor allows a catalyst to be designed at the nanoscale and enables the precise positioning of active sites on the surface of support rather than a sporadic dispersion, which is quite different from the case in zeolitic materials [113]. 
Another attractive feature of mesoporous catalysts is the possible immobilization of chiral catalysts in the nanopores. Most of the currently used enantioselective catalysts are based on noble metal organometallic species and used in homogeneous solution, which entails high cost, and difficulties in the separation of catalysts from products or substrates, and is catalyst recycling. It is therefore highly desirable to develop methods for the synthesis of heterogeneous analogs without losing the activity and selectivity of the homogeneous chiral catalysts. For example, cationic Rh(I) complexes containing a chiral diamino ligand and cyclooctadiene have been tethered on mesoporous silica. When used to catalyze the hydrogenation of methyl benzoylformate, enantiomeric excess (EE) values are actually boosted as compared to the homogeneous systems [114, 115].

Positively charged protonated amines can adsorb negatively charged polyoxometalates (POMs) through electrostatic attraction, which provides a way to load POMs on mesoporous silica with almost a monolayer dispersion inside the meso-channels. Negligible leaching has often been observed as a result of the strong interaction. The loaded POMs show reasonably good activity for $\mathrm{C}-\mathrm{H}$ bond activation and selective oxidation using $\mathrm{H}_{2} \mathrm{O}_{2}$ or air as the oxidant. For large substrates, it has been found that large-pore SBA-15 is more favorable than MCM-41 [116, 117]. Such ship-in-a-bottle synthesis of catalysts, taking advantage of the high surface area of mesoporous materials and surface silanol groups to anchor the desired active sites within a confined nanoscale space, represents a new trend in heterogeneous catalysis.

\section{Design of catalysts on nanoparticle surfaces}

Catalytic properties of nanomaterials rely strongly on the stabilization techniques employed to avoid aggregation during their preparation. So far, most of the catalysts using nanoparticles as active species originate from supported nanoparticles on high surface area porous solids, for which post-synthetic methods such as wet impregnation, grafting, and deposition are normally adopted. As an alternative, self-assembly of nanoscale building blocks to form organized heterogeneous catalysts can broaden our methods of preparation and give materials which show extraordinary activity and selectivity in catalysis. Some examples in the literature are described below.

\subsection{Self-assembly of polyoxometalate nano- particles}

Polyoxometalates (POMs) are composed of negatively charged inorganic metal-oxygen building blocks and cations. The charge balancing polyanions and cationic species can self-assemble into threedimensional structures with specific topological and electronic structures at multilevel (hierarchical) length scales $[118,119]$. The composition of POMs can vary from isopolyoxometalates with the general formula $\left[\mathrm{M}_{x} \mathrm{O}_{y}\right]^{n-}$ to heteropolyoxometalates $\left[\mathrm{X}_{a} \mathrm{M}_{x} \mathrm{O}_{y}\right]^{n-}$, or even to mixed-addenda POMs with different ratios of elements such as $\left[\mathrm{X}_{a} \mathrm{M} 1_{x 1} \mathrm{M} 2_{x 2} \mathrm{O}_{y}\right]^{n-}$, where $\mathrm{M}$ can be $\mathrm{W}, \mathrm{Mo}$, $\mathrm{V}$, etc., and $\mathrm{X}$ can be $\mathrm{P}, \mathrm{Si}, \mathrm{Zn}$, etc.; $\mathrm{X}$ is a heteroatom in the center of POMs and stabilizes the structure. Apart from the frequently studied early transition metals such as $\mathrm{W}, \mathrm{Mo}$, or $\mathrm{V}$ that form the basic building units of POMs, other transition metals can substitute some of these atomic sites to introduce additional properties into POMs. The structures of POMs are as rich as their compositions. For instance, the Lindqvist structure is found in isopolyoxometalates with formula $\mathrm{M}_{6} \mathrm{O}_{19}{ }^{n-}$, while for heteropolyoxometalates the ball-like Keggin structure $\mathrm{XM}_{12} \mathrm{O}_{40}{ }^{n-}$, sandwich-like Dawson structure $\mathrm{X}_{2} \mathrm{M}_{18} \mathrm{O}_{62}{ }^{n-}$, and Anderson structure $\mathrm{XM}_{6} \mathrm{O}_{24}{ }^{n-}$ are commonly found. The coordination number for addenda atoms can vary from 4,6 to 8 or even 12 . The chemical state of the transition metals can also change with the structure or composition of a POM. Furthermore, there are defects in the so-called lacunary structures. The POMs can also self-assemble into ordered patterns at the nanometer scale, and thus have multilevel ordered structures [120, 121]. The great diversity in composition and structure of POMs make them attractive materials in many fields [122]. One of the focuses is to use them as catalysts in oxidation and acid promoted reactions. POMs exhibit catalytic activity in oxidation of olefins to epoxides, oxidative

\section{算 Springer}


dehydrogenation of alkanes, or isomerization reactions by virtue of their redox and acidic properties, which have drawn much attention in both homogeneous and heterogeneous catalysis [123-125]. POMs themselves are non-porous solids with surface area of less than $10 \mathrm{~m}^{2} / \mathrm{g}$ and the acidic protons sites are in the interior of the solid and are not available to substrates for heterogeneous catalysis. For non-polar substrates, catalytic reactions occur mainly on POM surfaces, whereas polar molecules are absorbed in POMs to form a pseudo-liquid state before catalytic reactions. In order to enlarge the surface area, POMs have been supported on inert or weakly acidic high surface area materials, and self-assembly techniques are also being developed [125, 126].

\subsubsection{Self-assembly of polyoxometalate nanoparticles with} cations

Substitution of protons in $\mathrm{H}_{3} \mathrm{PW}_{12} \mathrm{O}_{40}$ with large $\mathrm{Cs}^{+}$cations induces a self-assembly of the Keggin polyanions, and thus forms a homogeneous composite material with interparticle mesoporosity. The polyanions emulate the catalytic activities of other solid acids such as zeolites or superacids like $\mathrm{SO}_{4}{ }^{2-} / \mathrm{ZrO}_{2}$ for isomerization of $n$-pentane and n-hexane and coking is circumvented in the gas phase reaction [126, 127]. In some cases, addition of cations can produce micropores in the salts resulting in shape selectivity. Since $\mathrm{Cs}^{+}$is large in diameter, it can expand the lattice and dissolve in the Keggin structures [128, 129]. For liquid phase reactions, it is desirable to employ heterogeneous catalysts for simplicity in separation and recycling processes.
One good example of the use of POMs was recently reported by Hill and co-workers in the selective sulfoxidation by $\mathrm{O}_{2}$ of 2-chloroethyl ethyl sulfide to give the corresponding less toxic sulfoxide under ambient aerobic conditions. Cation exchange of $\mathrm{AgNO}_{3}$, which is an effective catalyst for this reaction in homogeneous systems, with $\mathrm{Na}_{5} \mathrm{PV}_{2} \mathrm{Mo}_{10} \mathrm{O}_{40}$ in water produces an insoluble compound $\mathrm{Ag}_{5} \mathrm{PV}_{2} \mathrm{Mo}_{10} \mathrm{O}_{40}$, which converts the homogeneous system to an efficient heterogeneous one [130]. Mizuno and Yamaguchi synthesized a mono-ruthenium substituted POM, $\left[\left(n-\mathrm{C}_{4} \mathrm{H}_{9}\right)_{4} \mathrm{~N}\right]_{4} \mathrm{H}$ $\left[\mathrm{SiW}_{11} \mathrm{Ru}^{\mathrm{III}}\left(\mathrm{H}_{2} \mathrm{O}\right) \mathrm{O}_{39}\right] \cdot 2 \mathrm{H}_{2} \mathrm{O}$, by reaction of $\mathrm{RuCl}_{3}$ with a lacunary silicotungustate in an organic medium. This system exhibits high catalytic activity towards selective aerobic oxidation of alkanes/alcohols to the corresponding alcohols/aldehydes, respectively, with high turnover numbers [131]. In this work, the authors carefully studied the catalytic activity of the small amount of leached species, excluding the possibility that the reaction is driven by homogeneous metal cations and confirmed that the activity is derived from the insoluble POMs.

More recently, $\mathrm{Xi}$ and co-workers developed an interesting phase transfer catalytic reaction system using a cetylpyridineammonium-containing POM, $\left[\pi-\mathrm{C}_{5} \mathrm{H}_{5} \mathrm{NC}_{16} \mathrm{H}_{33}\right]_{3}\left[\mathrm{PO}_{4}\left(\mathrm{WO}_{3}\right)_{4}\right]$. The POM catalyzes the epoxidation of propylene to propylene oxide by $\mathrm{H}_{2} \mathrm{O}_{2}$ in a homogeneous system in 2-ethylanthrahydroquinone as solvent. The $\mathrm{H}_{2} \mathrm{O}_{2}$ is consumed as the reaction proceeds, and the POM salts out as a result of the decrease in its solubility. This system, shown in Fig. 7, is interesting because it combines the

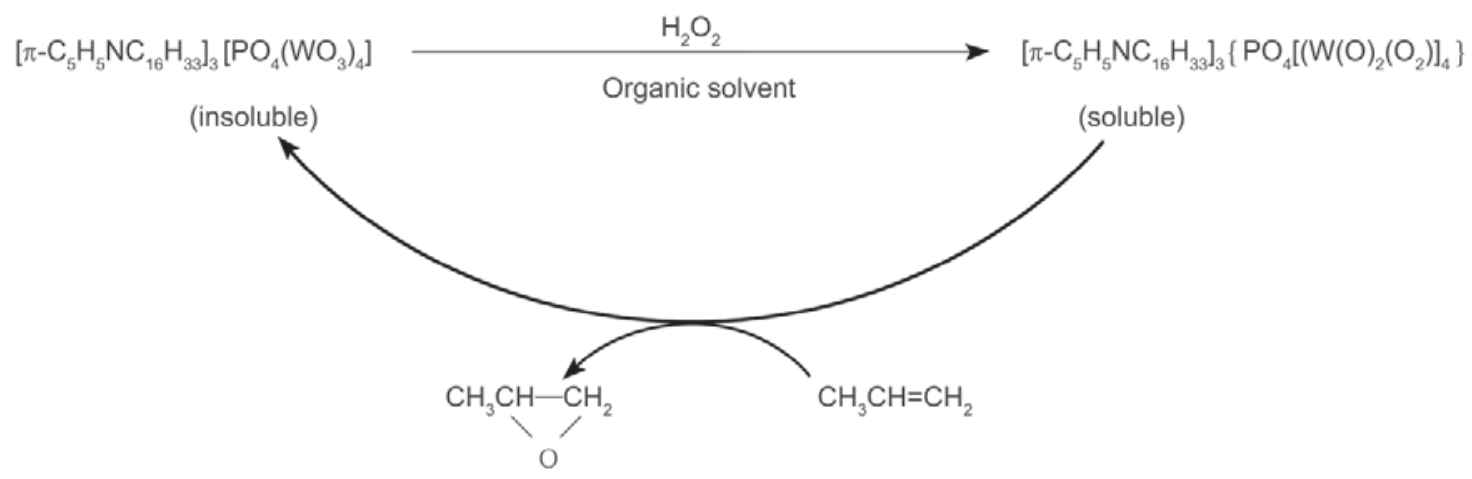

Figure 7 Phase transportation in a POM system driven by $\mathrm{H}_{2} \mathrm{O}_{2}$ consumption [132] (Copyright American Association for the Advancement of Science. Reproduced with permission) 
benefits of homogeneous and heterogeneous systems, and the separation of the catalyst from solution is automatically driven by the consumption of the oxidant $\mathrm{H}_{2} \mathrm{O}_{2}[132,133]$. Generally speaking, the type of counter cation determines the solubility of POMs, and normally metal cations lead to reduced solubility in organic solvents [128, 129].

Complexation of POMs with cationic species can also create pores with crystalline pore walls. For example, reaction of a Keggin-type $\left[\alpha-\mathrm{SiW}_{12} \mathrm{O}_{40}\right]^{4-}$ complex with $\left[\mathrm{Cr}_{3} \mathrm{O}(\mathrm{OOCH})_{6}\left(\mathrm{H}_{2} \mathrm{O}\right)_{3}\right]^{+}$affords a crystalline material, $\mathrm{K}_{3}\left[\mathrm{Cr}_{3} \mathrm{O}(\mathrm{OOCH})_{6}\left(\mathrm{H}_{2} \mathrm{O}\right)_{3}\right][\alpha-$ $\left.\mathrm{SiW}_{12} \mathrm{O}_{40}\right] \cdot 16 \mathrm{H}_{2} \mathrm{O}$, with well-ordered pores of 0.5 $\mathrm{nm} \times 0.8 \mathrm{~nm}$, as shown in Fig. 8 . The porous matrix shows preferential adsorption of small alcohols and nitriles whose molecular size matches the pore diameters [134]. A related zeolitic type material, $\mathrm{Cs}_{5}\left[\mathrm{Cr}_{3} \mathrm{O}(\mathrm{OOCH})_{6}\left(\mathrm{H}_{2} \mathrm{O}\right)_{3}\right]\left[\alpha-\mathrm{CoW}_{12} \mathrm{O}_{40}\right] \cdot 7.5 \mathrm{H}_{2} \mathrm{O}$, exhibits high selectivity for water sorption in the presence of alcohols [135]. The observed selectivity was rationalized in terms of energetic changes during the sorption process, and is quite similar to that found in molecular sieves and metal-organic framework materials (MOFs) [136]. More interestingly, the hydrophobicity/hydrophilicity is tunable by changing the type of macrocation. For example, $\left[\mathrm{Cr}_{3} \mathrm{O}(\mathrm{OOCH})_{6}\left(\mathrm{H}_{2} \mathrm{O}\right)_{3}\right]^{+}$complexes with Keggintype polyoxometalates $\left[\alpha-\mathrm{XW}_{12} \mathrm{O}_{40}\right]^{n-}(n=3-6)$ and alkali cations to produce hydrophilic channels, while hydrophobic channels form when only the macrocation
$\left[\mathrm{Cr}_{3} \mathrm{O}(\mathrm{OOCH})_{6}\left(\mathrm{H}_{2} \mathrm{O}\right)_{3}\right]^{+}$is employed. Using the related macrocation $\left[\mathrm{Cr}_{3} \mathrm{O}\left(\mathrm{OOCC}_{2} \mathrm{H}_{5}\right)_{6}\left(\mathrm{H}_{2} \mathrm{O}\right)_{3}\right]^{+}$affords both hydrophobic and hydrophilic channels in the same structure [134, 135, 137, 138]. In the case of Dawson-type polyoxometalates of the type $\left[\alpha-\mathrm{P}_{2} \mathrm{~V}_{x} \mathrm{~W}_{18-x} \mathrm{O}_{62}\right]^{(6+x)-}$, the micropore size of the ionic crystal is found to decrease with increasing vanadium incorporation $(x)[139,140]$. Although these self-assembled systems have shown high selectivity in separating water and various alcohols, so far no catalytic activity has been reported using such POM based microporous materials. Application of these materials under mild reaction conditions can be anticipated, but the thermal stability of these structures is still a concern under harsh catalytic reaction conditions [140].

2.1.2 Self-assembly of polyoxometalate nanoparticles with positively charged nanoparticles

Hill and co-workers recently designed POMbased catalysts through self-assembly induced by cationic $\left(\mathrm{Si} / \mathrm{AlO}_{2}\right)^{n+}$ nanoparticles, where ionexchange of the their charge-balancing $\mathrm{Cl}^{-}$anions with POMs is driven by the stronger interactions between the positively charged nanoparticles and the polyanions. A monolayer of POM is immobilized on the surface of the nanoparticles and can function as a heterogeneous catalyst in a liquid system. Aerobic oxidation of tetrahydrothiophene to tetrahydrothiophene oxide under ambient conditions is catalyzed by $\left\{\mathrm{K}_{8}\left[\left(\mathrm{Fe}^{\mathrm{III}}\left(\mathrm{OH}_{2}\right)_{2}\right)_{3}\left(\mathrm{PW}_{9} \mathrm{O}_{34}\right)_{2}\right]\right\}_{58}\left(\mathrm{Si} / \mathrm{AlO}_{2}\right)$,

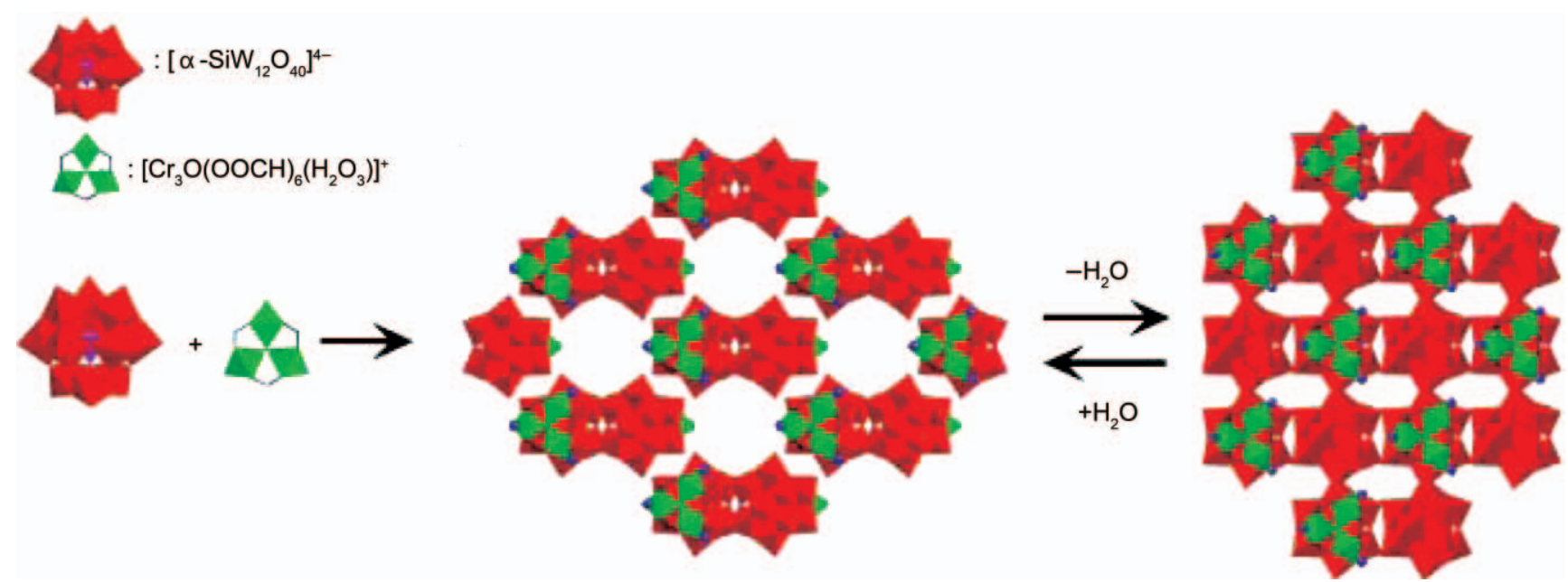

Figure 8 Synthesis and crystal structure of $\mathrm{K}_{3}\left[\mathrm{Cr}_{3} \mathrm{O}(\mathrm{OOCH})_{6}\left(\mathrm{H}_{2} \mathrm{O}\right)_{3}\right]\left[\alpha-\mathrm{SiW}_{12} \mathrm{O}_{40}\right] \cdot 16 \mathrm{H}_{2} \mathrm{O}$ and the ideal closest-packing model of the material obtained after desorption of water molecules by evacuation at $298 \mathrm{~K}$. The water of crystallization is omitted for clarity; small blue spheres are $\mathrm{K}^{+}$ ions [134] (Copyright Wiley-VCH Verlag GmbH \& Co. KGaA, Weinheim. Reproduced with permission) 
with a turnover number of 60 , as compared with 2.2 for the unsupported POM. Dynamic light scattering (DLS) and microscopy images confirm that the POMs are evenly distributed on the cationic nanoparticle surfaces as a monolayer [141, 142]. An increased turnover number with respect to the homogeneous system is also observed for aerobic oxidation of 2-chloroethyl ethyl sulfide aerobic oxidations [143].

\subsubsection{Intercalated polyoxometalates}

Intercalation of POMs into layered compounds through the chimie douce method is an alternative way to load POMs on high surface area layered supports. The expansion of interlayer spacing will produce a microporous material with POMs accessible between the layers of the support [144-147]. A variety of hosts, including hydrotalcite-like materials (layered double hydroxides, LDHs), layered perovskites, clays, and pillared clays are frequently used in catalysis. LDHs are made up of stacks of positively charged brucite-like layers and negatively charged anionic with improved catalytic activity (turnover frequency of 18000 at a temperature of $50{ }^{\circ} \mathrm{C}$ ) [146]. Jana and co-workers found that $\alpha-\left\{\left[\mathrm{SiW}_{9} \mathrm{O}_{37} \mathrm{Co}\left(\mathrm{H}_{2} \mathrm{O}\right)_{3}\right]\right\}^{10-}$ intercalated into an LDH can catalyze the aerobic oxidation of cyclohexanol at ambient pressure under mild conditions, and that the heterogeneous catalysts can be recycled [148]. Liu and co-workers reported that LDHs can be intercalated by peroxopolyoxometalates when treated with $\mathrm{H}_{2} \mathrm{O}_{2}$ after ionexchange, as shown in Fig. 9. When $\left[\mathrm{PW}_{11} \mathrm{O}_{39}\right]^{7-}$ was intercalated into a $\mathrm{Pd} / \mathrm{M} / \mathrm{Al}-\mathrm{LDH}\left(\mathrm{M}=\mathrm{Mg}^{2+}\right.$ or $\mathrm{Zn}^{2+}$ ) and the resulting material used to catalyze the epoxidation of propylene in methanol by $\mathrm{O}_{2}$, a conversion of $47.5 \%$ was obtained after $10 \mathrm{~h}$ in methanol at $80^{\circ} \mathrm{C}$ [149]. Some POMs in homogeneous systems are active for photocatalysis, but supported POMs are normally not so active as the support can absorb light [119]. Pinnavaia and co-workers have reported that an $\mathrm{LDH},\left[\mathrm{Zn}_{2} \mathrm{Al}(\mathrm{OH})_{6}\right] \mathrm{NO}_{3} \cdot x \mathrm{H}_{2} \mathrm{O}$, pillared by Keggin structured $\left[\mathrm{XM}_{12} \mathrm{O}_{40}\right]^{n-}$ is active for the photocatalytic conversion of propanol to acetone. layers. For instance, hydrotalcite is composed of $\mathrm{Mg}_{3} \mathrm{Al}(\mathrm{OH})_{8}^{+}$cationic layers and $\mathrm{CO}_{3}{ }^{2-}$ layers. LDHs are traditionally employed as basic catalysts for reactions such as ethylation, alkylation, isomerisation, esterification, hydrodealkylation, hydro-dehydrogenation, and ring opening. LDHs can be also ion-exchanged with anions or complexes to form a variety of intercalated compounds. This topic has been extensively reviewed [147]. POMs can also be inserted into the interlayer galleries to form supported heterogeneous catalysts. The size and type of POMs determine the spacing between the layers as well as the porosity. Li and co-workers recently found that under certain conditions metal salts can selfassemble with LDHs to form in situ immobilized POMs, which catalyze the epoxidation of allylic alcohols


Figure 9 Synthesis route for layered double hydroxides intercalated by peroxopolyoxometalates [149] (Copyright Elsevier, Inc. Reproduced with permission) 
Only the POMs with $n>4$ can be ion-exchanged by virtue of their strong interaction with the cationic layers in the clay [150, 151]. Normally, for such ionexchange reactions, the $\mathrm{pH}$ needs to be adjusted to match the stability of both LDHs and POMs. Most POMs are preserved after the ion-exchange [145, 151]. The intercalated POMs are mainly used in catalysis under mild conditions, as their structures may collapse at high temperatures or under other forcing conditions.

\subsection{Dendrimer encapsulated nanoparticles and complexes as catalysts}

Dendrimers are a series of macromolecules with specific molecular weight and structure that have been developed over the past 40 years. Their shape resembles trees or cauliflowers and form nanoscale spaces under the termini layers between the branches [152]. Some metallodendrimers are catalytically active by themselves as homogeneous catalysts, while others can assemble with metal complexes or nanoparticles to form heterogeneous catalysts [153]. Metal nanoparticles can give high conversion and yields in catalysis due to their high surface area and size-dependent properties; however, selectivity is hard to achieve without surface modifications [27]. Dendrimer entrapped metal nanoparticles have shown size selectivity in heterogeneous catalysis [153-158]. The preparation of encapsulated metal particles begins with a solution of metal cations. The cations, when mixed with dendrimers, will be immobilized through complexation. Subsequent reduction of the cations produces metal particles. The metallic particles are normally within the nanoscale as a result of the dendrimer confinement. The solubility of the resulting heterogeneous catalyst is dependent on the solubility of the dendrimers. Once the metal nanoparticles are entrapped inside the internal spaces, only substrates smaller than the terminal gates can reach the catalytic centers and undergo reaction, while larger ones are excluded. In an examination of the hydrogenation of allyl alcohols by $2 \mathrm{~nm}$ Pd nanoparticles encapsulated within hydroxyl-terminated poly(amidoamine) dendrimers, Crooks and co-workers found that the turnover frequency drops as the molecular size of substrates increases or when the packing density on the dendrimer periphery is enhanced [157]. The mechanism of the size-selective catalysis is shown schematically in Fig. 10. This concept has been extended to bimetallic alloys and coreshell type nanoparticles, showing the versatility of these materials in respect of control of particle size,
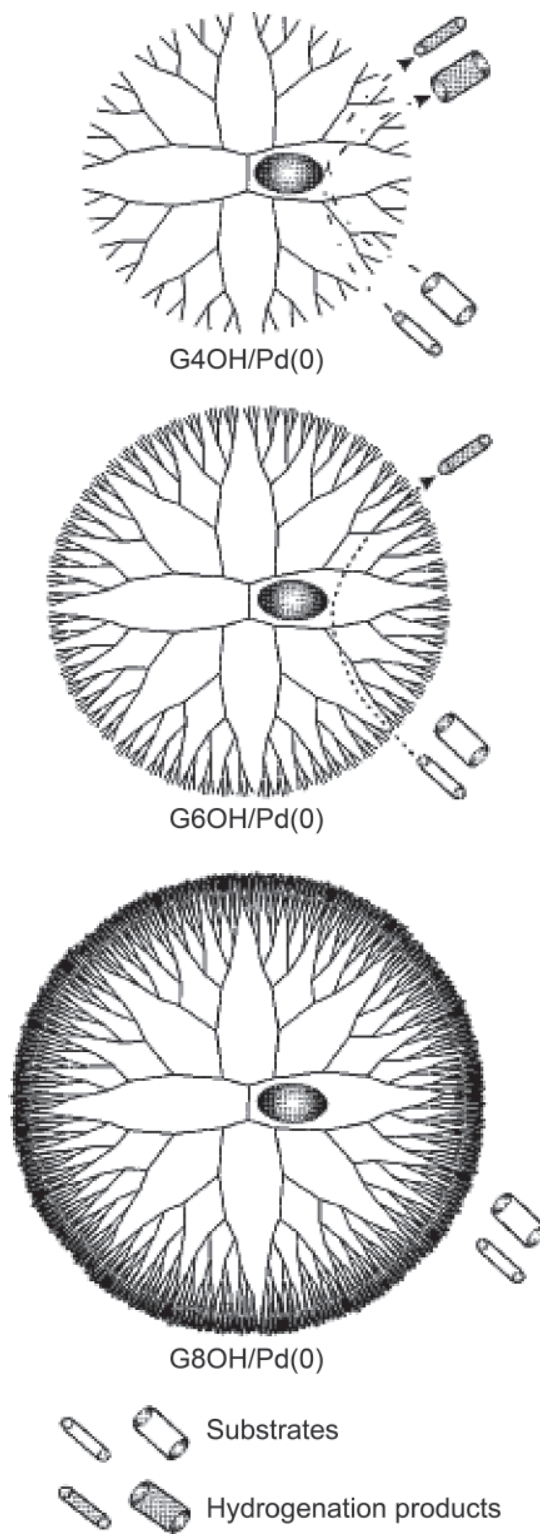

Figure 10 Crooks's method for nanoparticles encapsulated in poly(amidoamine) (PAMAM) or poly(propyleneimine) (PPI) dendrimers. Complexation of a metal cation to the inner nitrogen atoms of tertiary amines, then reduction to metals by $\mathrm{NaBH}_{4}$, and partial aggregation produces particles within the dendrimer; size and shape selectivity are imposed by the peripheries [157]. (Copyright American Chemical Society. Reproduced with permission) 
composition, and structure [81, 155, 157, 159, 160]. For the same type of hydrogenation reaction, a coreshell structure is superior to a mixed alloy in catalytic activity [157]. The use of nanoparticles as catalysts is one future trend for heterogeneous catalysis as part of a more general focus on nanoscience and nanotechnology [155].

Dendrimers with chiral groups can also be used as enantioselective catalyst promoters when metal complexes/nanoparticles are trapped inside the inner space of dendrimers or when active sites are covered by them [156, 161-163]. Moreover, $3 \mathrm{~nm}$ $\mathrm{PdAu}$ bimetallic nanoparticles supported on titania can be prepared from a dendrimer encapsulated metallic precursor; the material exhibits improved catalytic activity in $\mathrm{CO}$ oxidation reactions compared with the monometallic counterparts. These results show the possibility of incorporating nanoparticles into bulk supports to avoid handling nanoparticles directly in heterogeneous catalysis [164]. Dendrimers with functional ester groups can self-assemble with $\left[\mathrm{H}_{4} \mathrm{P}_{2} \mathrm{~V}_{3} \mathrm{~W}_{15} \mathrm{O}_{62}\right]^{5-}$ through complexation into macromolecular structures, which catalyze the liquid phase oxidation of tetrahydrothiophene using $\mathrm{H}_{2} \mathrm{O}_{2}$ or tert-butyl peroxide with high activity [165].

Applications of dendrimers in catalysis can vary from homogeneous to heterogeneous systems, for reactions ranging from oxidations, hydrogenations, to asymmetric, as well as enzymatic catalysis. Some recent reviews are available for a more complete outlook [153, 154].

\section{Surface control and activity of nano- structured catalysts}

Nanoscale materials with well-defined shapes possess unique crystalline surfaces, surface orientations, surface edges, size, and shapes, and have potential applications in catalysis depending on the morphology and electronic structures of the supports employed. For catalytic applications, onedimensional nanomaterials such as nanotubes, nanowires, and nanorods have received great attention. One such material, tubular nanomaterial titanate nanotubes (TNT), was first synthesized by Kasuga and co-workers in 1998 using strongly alkaline aqueous solutions. The sodium ion in the asprepared TNT can be ion-exchanged in a similar way to zeolites [166, 167]. Ion-exchange of ruthenium ions with TNT can produce hydrated $\mathrm{Ru}(\mathrm{III})$ oxide on their surfaces. The catalyst has a turnover frequency of $450 \mathrm{~h}^{-1}$ in aerobic oxidation of benzyl alcohol, which is superior to other supports [168]. Pt, Pd, and Au nanoparticles with diameter less than $5 \mathrm{~nm}$ can be deposited on TNT through ion-exchange and subsequent reduction by $\mathrm{NaBH}_{4}$. A surfactant, di-dodecyldimethylammonium chloride was used to cover the outer surfaces before ion-exchange to ensure the nanoparticles are formed inside the channels [169]. As a semiconductor, zinc ion-exchanged TNT has also been used in photocatalysis for the degradation of methyl orange in water. Uptake of zinc has no effect on the structure of the support and it is found to reside mainly on the surface and its inclusion improves the photocatalytic activity [170].

$\mathrm{CeO}_{2}$ nanorods can be synthesized in strongly alkaline media, and are found to be active for $\mathrm{CO}$ oxidation. The catalytic activity is enhanced when $\mathrm{Au}$ nanoparticles are deposited on the nanorods [171]. $\mathrm{ZnO}$ has a hexagonal structure and normally prefers to grow along the $c$-axis to give wire/rod structures. $\mathrm{An} \mathrm{Au} / \mathrm{ZnO}$ nanorod composite is able to catalyze the degradation of methyl orange under 365 $\mathrm{nm}$ irradiation. It is found that the activity is highly dependent on the size of the Au nanoparticles [172].

Two-dimensional nanomaterials with sheet morphology are highly interesting for catalysis because their surface properties are controllable and can be optimized with respect to their catalytic activity. One example, an $\mathrm{MgO}(111)$ nanosheet structure, is discussed here. In $\mathrm{MgO}$, a typical ionic solid with the rock salt structure, the (100) surface of $\mathrm{Mg}^{2+}$ and $\mathrm{O}^{2-}$ ions is unambiguously the most stable due to the low surface energy. The (111) surface of $\mathrm{MgO}$ is made up of alternating layers of oxide anions and magnesium cations. Thereby, a polarity perpendicular to the surface is created on the (111) surface, which is categorized as a Tasker type III surface by surface scientists [173]. Such a surface has attracted great attention as a results of its unique surface properties and for its catalytic applications [174, 175]. Most studies on powdered 
$\mathrm{MgO}$ are restricted to thermally prepared $\mathrm{MgO}$. The best catalytic performances are achieved with $\mathrm{MgO}$ aerogels with sizes of $4 \mathrm{~nm}$ to $20 \mathrm{~nm}$, or cubelike particles obtained by from chemical vapor deposition (CVD). The major surface of the cubes obtained by CVD is (100) and $\mathrm{MgO}$ aerogels have mixed surfaces [176, 177]. Zhu et al. used substituted benzyl alcohols as a template in a methanolwater magnesium solution to prepare a sheet-like magnesium hydroxyl methoxide. When heated under supercritical conditions to temperatures above $500{ }^{\circ} \mathrm{C}$, the magnesium hydroxyl methoxide decomposed into $\mathrm{MgO}$ nanosheets with (111) as the major surface [178]. Figure 11 shows TEM images and the structure of the $\mathrm{MgO}(111)$ nanosheet. For the Claisen-Schmidt condensation of benzaldehyde with acetophenone, the $\mathrm{MgO}(111)$ nanosheets showed higher catalytic activity than $\mathrm{MgO}$ aerogels. Considering that the surface area of aerogel is more than $500 \mathrm{~m}^{2} / \mathrm{g}$ and that of the nanosheet is only around $200 \mathrm{~m}^{2} / \mathrm{g}$, the activity per unit surface area of the $\mathrm{MgO}$ (111) nanosheets is even higher than that of $\mathrm{MgO}$ aerogels. This high activity can be rationalized in terms of surface orientation. As the (111) surface mainly exposes $\mathrm{Mg}^{2+} / \mathrm{O}^{2-}$ pairs, the surface is constituted of the medium-strength basic sites which are the active sites for the Claisen-Schmidt condensation reaction. Infrared and temperature programmed $\mathrm{CO}_{2}$ desorption confirmed that the surface properties are governed by the presence of $\mathrm{Mg}^{2+} / \mathrm{O}^{2-}$ pairs and $\mathrm{OH}$ groups. Infrared spectra during in situ adsorption of methanol showed that the surface is highly reactive towards decomposition of methanol and the surface $\mathrm{C}=\mathrm{O}$ species formed can be readily oxidized, owing to the oxygen-rich (111) surfaces [179]. Benzyl alcohols are commonly used in anhydrous solutions to template nanoparticles [180, 181]. In the synthesis of the $\mathrm{MgO}(111)$ nanosheets, water is necessary to hydrolyze the magnesium methoxide. This synthetic strategy can be extended to prepare p-type semiconductor $\mathrm{NiO}$ with polar surfaces and hexagonal holes surrounded by crystalline edges [182]. The role of the benzyl alcohols in this case is still not clear, but it is believed that the self-assembly involves the interaction between the $-\mathrm{OH}$ groups of the benzyl alcohol and that of $\mathrm{Mg}(\mathrm{OH})\left(\mathrm{OCH}_{3}\right)$.
The hydroxyl group in benzyl alcohols is weakly acidic whilst that in $\mathrm{Mg}(\mathrm{OH})\left(\mathrm{OCH}_{3}\right)$ is basic. By heating the mixture under supercritical conditions, the interaction between them is enhanced so that the surface orientation of $\mathrm{Mg}(\mathrm{OH})\left(\mathrm{OCH}_{3}\right)$ is tailored. The $\mathrm{MgO}(111)$ surface becomes the major surface after thermal decomposition. The successful synthesis of $\mathrm{NiO}$ can be attributed to the similarities between $\mathrm{MgO}$ and $\mathrm{NiO}$ : (1) both metals can form metal hydroxyl methoxides under hydrothermal conditions, and (2) $\mathrm{MgO}$ and $\mathrm{NiO}$ have the same rock salt structure [182].

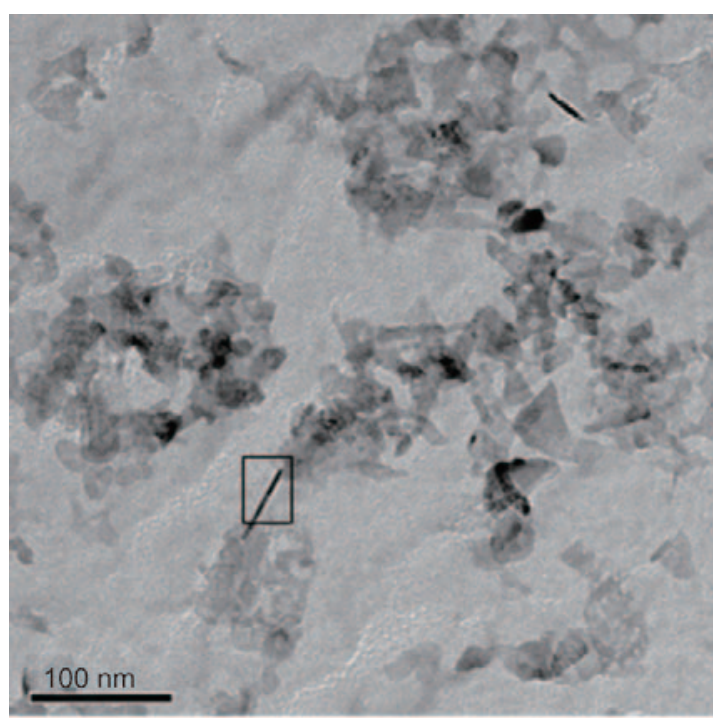

(a)

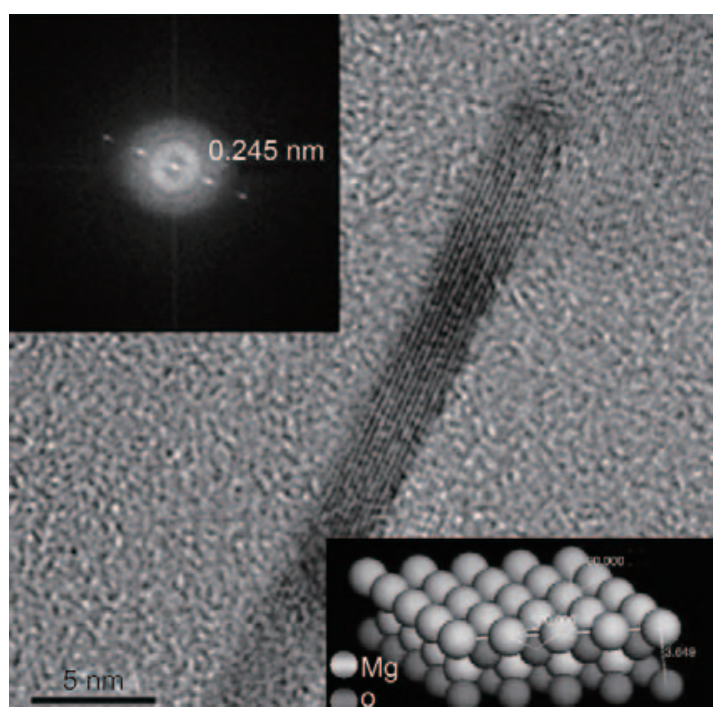

(b)

Figure 11 TEM images of $\mathrm{MgO}$ nanosheets and a model for the surface of $\mathrm{MgO}(111)$ [178] (Copyright Wiley-VCH Verlag GmbH \& Co. KGaA, Weinheim. Reproduced with permission) 
Table 1 Catalytic properties of mesoporous MFI zeolite and other aluminosilicate materials

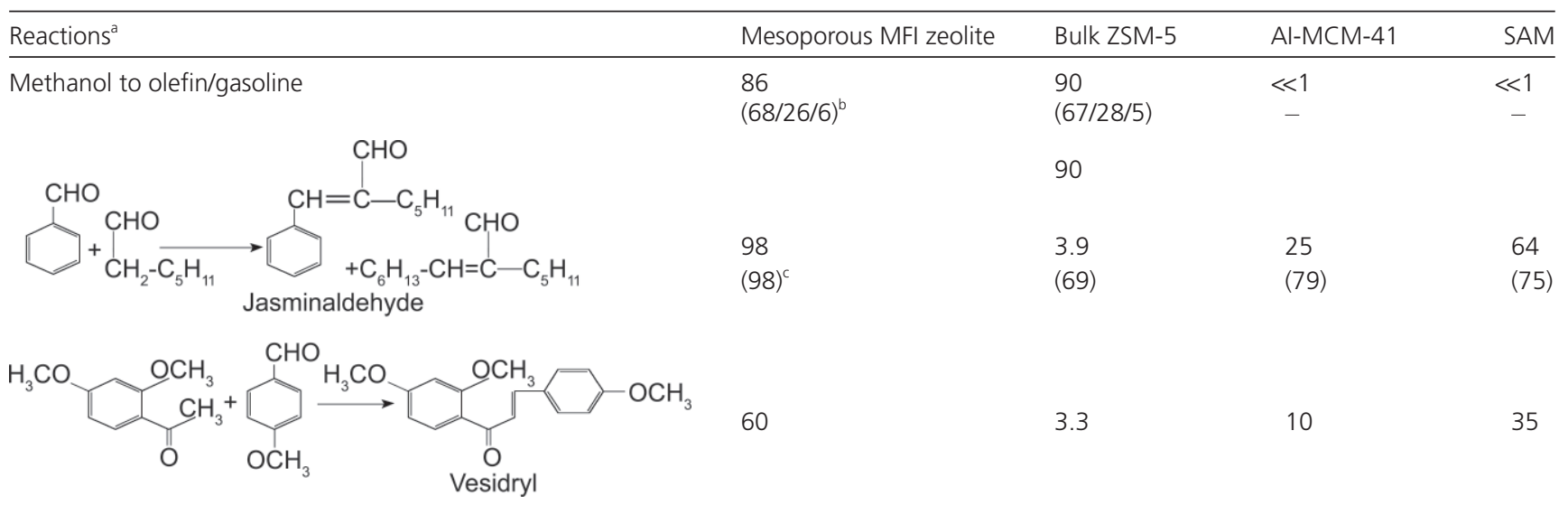

\footnotetext{
${ }^{a}$ Catalytic activities were compared on the basis of the same weight of catalysts. All catalysts had the same Si/Al = 20. The Brunauer-EmmettTeller (BET) surface area was 590 m²/g for mesoporous MFI, 350 m²/g for ZSM-5, $948 \mathrm{~m}^{2} / \mathrm{g}$ for Al-MCM-41, and 923 m²/g for SAM (MCM-41-type).

${ }^{\mathrm{b}}$ The numbers in parentheses represent \% selectivity (olefin/gasoline/others).

' Jasminaldehyde selectivity. All other numbers indicate the reactant conversion (\%)

(Copyright Nature Publishing Group. Reproduced with permission) [63]
}

Control of orientation of metal oxides is also important for a fundamental understanding of catalysis, as they provide model systems for surface structures and their catalytic activity. Currently, studies on surface orientated metal oxides are restricted by the lack of appropriate methods to control surfaces. Unstable surfaces are normally more active for catalysis, as they have more dangling bonds on their surfaces; that is why non-crystalline catalysts are more active than crystalline ones. Since non-crystalline solids are normally less stable, a crystalline nanomaterial exposing an unstable surface can combine the merits of both crystalline and noncrystalline catalysts; the Tasker type III surface is exactly this kind of surface as shown above. Surface scientists provide us with knowledge of which are the active sites for a certain reaction, and to synthesize a material with the maximum number of such active sites and use it in large scale catalysis is a rational way to develop future catalysts. This needs collaboration and cutting-edge studies in order to bridge the gaps between heterogeneous catalysis and materials science.

\section{Perspectives}

Self-assembly of molecules, molecular seeds, and nano building blocks into organized structures provides new opportunities to tailor catalytically active structures and porosities simultaneously. Selfassembly has improved the design and synthesis of heterogeneous catalysts, from microporous zeolites to mesoporous and nanometer scale materials. Developments in mechanistic studies of self-assembly processes enable us to design and synthesize new materials for catalytic applications. Numerous improvements in terms of our basic understanding of structure-activity relationships, as well as new catalytic systems have been made [45, 47].

Despite the considerable progress, many challenges still remain for these new materials: (1) Synthesis of materials with multiple components and multi-functions by self-assembly are highly desirable. As many of the commercially used catalysts have more than one component, it is important to extend synthetic strategies to multicomponent systems, such as mixed metal oxides, and strongly acidic or basic systems. (2) The nature of the nano-, micro- and surface structures of some systems or mechanisms of formation are still not clear, and tailoring of the structure and distribution of active sites is still difficult. As exemplified by the $\mathrm{MgO}(111)$ sheet material described above, control of the surface orientation can promote the 
catalytic activity, as the more common (100) surface has different base sites from the unstable (111) surface. It is interesting to speculate whether other types of Tasker type III surfaces, for instance, the fluorite structured $\mathrm{CeO}_{2}(100)$ surface or the wurtzite structured $\mathrm{ZnO}(001)$ surface - which also involve alternate packing of oxide anions and metal cationswill exhibit novel catalytic activities. Although there have been many surface studies on single crystals, it is important to synthesize powders with preferential orientations. The tailored surface of powder samples on the nanoscale will increase the surface area of the material, and syntheses of such materials have the potential to be scaled up for use in applied catalysis. Studies on tailored surfaces of nano-powders will bridge the gap between surface science, catalysis, and material design. From the point of view of catalysis, this is important in order to improve activity by altering the surfaces, rather than the composition. (3) Stabilities of these meso- or nano- materials can be a problem for their applications under forcing reaction conditions, like high temperature, high pressure or under steaming. Pore confinement of crystals, surface anchoring by forming bonds with -OH groups, in situ synthesis by embedding metal centers inside the pore walls, or anchoring with surface functional groups are frequently used to stabilize the active species on the surfaces of catalysts. However, for reactions that produce heat or need to be performed under harsh thermal or hydrothermal conditions, stability of non-crystalline walls is still a potential threat to stability. (4) Many syntheses will be hard to scale up. Syntheses of most intercalated compounds take days, or even weeks, and are therefore less likely to be used in industry. Preparation of nano-sized zeolites is not only time consuming, but also gives rise to problems in handling. $\mathrm{CeO}_{2}$ nanoparticles used as precursors for self-assembly to form mesophases are also complicated to prepare and separate. Such problems can prevent the viable scaling up of the synthesis of such materials. (5) Leaching is still a problem in liquid phase reactions as the result of the weak surface anchoring of active species. So far, TS-1 is one the few catalysts resistant to leaching in liquid phase catalysis. Most anchored metal species suffer from leaching problems, and the catalysts deactivate quickly after several cycles; in situ synthesized metalcontaining mesoporous materials can also undergo leaching into solution during liquid phase catalysis. (6) Cost needs to be reduced. Most research on the synthesis of self-assembled materials emphasizes the structure and novelty in activity or selectivity, with little consideration of the expensive precursors used to prepare them or the cost of processes to produce them. At the beginning stage, it is easy to recognize new properties and structures, but in the long run for future applications, low cost routes need to be developed. (7) Environmental impact should be considered. Especially for nanoscale materials such as aerogels or nanoparticles in powder form, the impact on human health and the environment are still unknown. Studies of these potential hazards will help us to understand the materials and may establish new regulations on their usage. We believe that future efforts should be made towards solving these problems for self-assembled materials, particularly for use in heterogeneous catalysis.

\section{References}

11] National Research Council Panel on New Directions in Catalytic Sciences and Technology, Catalysis Looks to the Future; National Academy Press: Washington D. C., 1992.

[2] Huber, G. W.; Chheda, J. N.; Barrett, C. J.; Dumesic, J. A. Production of liquid alkanes by aqueous-phase processing of biomass-derived carbohydrates. Science 2005, 308, 1446-1450.

[3] Armor, J. N. Catalysis and the hydrogen economy. Catal. Lett. 2005, 101, 131-135.

[4] Olah, G. A. Beyond oil and gas: The methanol economy. Angew. Chem. Int. Edit. 2005, 44, 2636-2639.

[5] Sheldon, R. A. The $E$ factor: Fifteen years on. Green Chem. 2007, 9, 1273-1283.

[6] Thomas, J. M.; Thomas, W. J. Principles and Practice of heterogeneous Catalysis; Wiley-VCH: Weinheim, 1996.

[7] Jacobs, P. A.; Martens, J. A.; Weitkamp, J.; Beyer, H. K. Shape-selectivity changes in high-silica zeolites. Faraday Discuss. Chem. Soc. 1981, 72, 353-369.

[8] Haag, W. O.; Lago, R. M.; Weisz, P. B. Transport and reactivity of hydrocarbon molecules in a shape-selective zeolite. Faraday Discuss. Chem. Soc. 1981, 72, 317-330.

\section{(1. 国 Springer}


[9] Derouane, E. G.; Dejaifve, P.; Gabelica, Z.; Vedrine, J. C. Molecular shape selectivity of ZSM-5, modified ZSM-5 and ZSM-11 type zeolites. Faraday Discuss. Chem. Soc. 1981, 72, 331-344.

[10] Thomas, J. M.; Millward, G. R.; Ramdas, S.; Bursill, L. A.; Audier, M. New methods for the structural characterization of shape-selective zeolites. Faraday Discuss. Chem. Soc. 1981, 72, 345-352.

[11] Corma, A.; Rey, F.; Valencia, S.; Jorda, J. L.; Rius, J. A zeolite with interconnected 8-, 10- and 12-ring pores and its unique catalytic selectivity. Nat. Mater. 2003, 2, 493-497.

[12] Bond, G. C.; Thompson, D. T. Catalysis by gold. Catal. Rev. Sci. Engin. 1999, 41, 319-388.

[13] Bell, A. T. The impact of nanoscience on heterogeneous catalysis. Science 2003, 299, 1688-1691.

[14] Herzing, A. A.; Kiely, C. J.; Carley, A. F.; Landon, P.; Hutchings, G. J. Identification of active gold nanoclusters on iron oxide supports for CO oxidation. Science $\mathbf{2 0 0 8 ,}$ 321, 1331-1335.

[15] Nozaki, C.; Lugmair, C. G.; Bell, A. T.; Tilley, T. D. Synthesis, characterization, and catalytic performance of single-site iron(III) centers on the surface of SBA-15 silica. J. Am. Chem. Soc. 2002, 124, 13194-13203.

[16] Fujdala, K. L.; Drake, I. J.; Bell, A. T.; Tilley, T. D. Atomic level control over surface species via a molecular precursor approach: Isolated $\mathrm{Cu}(\mathrm{I})$ sites and $\mathrm{Cu}$ nanoparticles supported on mesoporous silica. J. Am. Chem. Soc. 2004, 126, 10864-10866.

[17] Maschmeyer, T.; Rey, F.; Sankar, G.; Thomas, J. $M$. Heterogeneous catalysis obtained by grafting metallocene complexes onto mesoporous silica. Nature 1995, 378, 159-162.

[18] Corma, A. From microporous to mesoporous molecular sieve materials and their use in catalysis. Chem. Rev. 1997, 97, 2373-2419.

[19] Breck, D. W. Zeolite Molecular Sieves; Robert E. Krieger Publishing Company Inc.: Malabar, FL, 1974.

[20] Tao, Y. S.; Kanoh, H.; Abrams, L.; Kaneko, K. Mesoporemodified zeolites: Preparation, characterization, and applications. Chem. Rev. 2006, 106, 896-910.

[21] van Donk, S.; Broersma, A.; Gijzeman, O. L. J.; van Bokhoven, J. A.; Bitter, J. H.; de Jong, K. P. Combined diffusion, adsorption, and reaction studies of $n$-hexane hydroisomerization over $\mathrm{Pt} / \mathrm{H}$-mordenite in an oscillating microbalance. J. Catal. 2001, 204, 272-280.
[22] Herrmann, C.; Haas, J.; Fetting, F. Effect of the crystal size on the activity of ZSM-5 catalysts in various reactions. Appl. Catal. 1987, 35, 299-310.

[23] Perez-Ramirez, J.; Kapteijn, F.; Groen, J. C.; Domenech, A.; Mul, G.; Moulijn, J. A. Steam-activated FeMFI zeolites. Evolution of iron species and activity in direct $\mathrm{N}_{2} \mathrm{O}$ decomposition. J. Catal. 2003, 214, 33-45.

[24] Zhu, K.; Wang, D.; Liu, J. Self-assembled materials for catalysis. In Design of Heterogeneous Catalysis: New Approaches based on Synthesis, Characterization and Modeling, Ozkan, U. S. ed. Wiley-VCH: Weinheim, 2009.

[25] Narayanan, R.; El-Sayed, M. A. Catalysis with transition metal nanoparticles in colloidal solution: Nanoparticle shape dependence and stability. J. Phys. Chem. B 2005, 109, 12663-12676.

[26] Ott, L. S.; Finke, R. G. Transition-metal nanocluster stabilization for catalysis: A critical review of ranking methods and putative stabilizers. Coord. Chem. Rev. 2007, 251, 1075-1100

[27] Astruc, D.; Lu, F.; Aranzaes, J. R. Nanoparticles as recyclable catalysts: The frontier between homogeneous and heterogeneous catalysis. Angew. Chem. Int. Ed. 2005, 44, 7852-7872.

[28] Chiola, V.; Ritsko, J. E.; Vanderpool, C. D. Process for producing low-bulk density silica. US Patent 3556725 1971.

[29] DiRenzo, F.; Cambon, H.; Dutartre, R. A 28-yearold synthesis of micelle-templated mesoporous silica. Micropor. Mater. 1997, 10, 283-286.

[30] Yanagisawa, T.; Shimizu, T.; Kuroda, K.; Kato, C. The preparation of alkyltrimethylammonium-kanemite complexes and their conversion to microporous materials. Bull. Chem. Soc. Japan. 1990, 63, 988-992.

[31] Inagaki, S.; Fukushima, Y.; Kuroda, K. Synthesis of highly ordered mesoporous materials from layered polysilicate. J. Chem. Soc. Chem. Commun. 1993, 680-682.

[32] Kresge, C. T.; Leonowicz, M. E.; Roth, W. J.; Vartuli, J. C.; Beck, J. S. Ordered mesoporous molecular-sieves synthesized by a liquid-crystal template mechanism. Nature 1992, 359, 710-712.

[33] Beck, J. S.; Vartuli, J. C.; Roth, W. J.; Leonowicz, M. E.; Kresge, C. T.; Schmitt, K. D.; Chu, C. T. W.; Olson, D. H.; Sheppard, E. W.; McCullen, S. B. et al. A new family of mesoporous molecular sieves prepared with liquid crystal templates. J. Am. Chem. Soc. 1992, 114, 10834-10843.

[34] Huo, Q. S.; Margolese, D. I.; Ciesla, U.; Feng, P. Y.; Gier, T. 
E.; Sieger, P.; Leon, R.; Petroff, P. M.; Schuth, F.; Stucky, G.

D. Generalized synthesis of periodic surfactant inorganic composite-materials. Nature 1994, 368, 317-321.

[35] Huo, Q. S.; Margolese, D. I.; Stucky, G. D. Surfactant control of phases in the synthesis of mesoporous silicabased materials. Chem. Mater. 1996, 8, 1147-1160.

[36] Yang, P. D.; Zhao, D. Y.; Margolese, D. I.; Chmelka, B. F.; Stucky, G. D. Generalized syntheses of largepore mesoporous metal oxides with semicrystalline frameworks. Nature 1998, 396, 152-155.

[37] Bagshaw, S. A.; Prouzet, E.; Pinnavaia, T. J. Templating of mesoporous molecular-sieves by nonionic polyethylene oxide surfactants. Science 1995, 269, 1242-1244.

[38] Tanev, P. T.; Pinnavaia, T. J. A neutral templating route to mesoporous molecular-sieves. Science 1995, 267, 865867.

[39] Zhao, D. Y.; Feng, J. L.; Huo, Q. S.; Melosh, N.; Fredrickson, G. H.; Chmelka, B. F.; Stucky, G. D. Triblock copolymer syntheses of mesoporous silica with periodic 50 to 300 angstrom pores. Science 1998, 279, 548-552.

[40] Zhao, D. Y.; Huo, Q. S.; Feng, J. L.; Chmelka, B. F.; Stucky, G. D. Nonionic triblock and star diblock copolymer and oligomeric surfactant syntheses of highly ordered, hydrothermally stable, mesoporous silica structures. J. Am. Chem. Soc. 1998, 120, 6024-6036.

[41] Chen, C. Y.; Burkett, S. L.; Li, H. X.; Davis, M. E. Studies on mesoporous materials II. Synthesis mechanism of MCM-41. Micropor. Mater. 1993, 2, 27-34.

[42] Stucky, G. D.; Monnier, A; Schuth, F.; Huo, Q. S.; Margolese, D.; Kumar, D.; Krishnamurty, M.; Petroff, P.; Firouzi, A.; Janicke, M.; Chemlka, B. F. Molecular and atomic arrays in nanoporous and mesoporous materials synthesis. Mol. Cryst. Liq. Cryst. 1994, 240, 187-200.

[43] Huo, Q. S.; Margolese, D. I.; Ciesla, U.; Demuth, D. G.; Feng, P. Y.; Gier, T. E.; Sieger, P.; Firouzi, A.; Chmelka, B. F.; Schuth, F.; Stucky, G. D. Organization of organicmolecules with inorganic molecular-species into nanocomposite biphase arrays. Chem. Mater. 1994, 6, 1176-1191.

[44] Firouzi, A.; Kumar, D.; Bull, L. M.; Besier, T.; Sieger, P.; Huo, Q. S.; Walker, S. A.; Zasadzinski, J. A.; Glinka, C.; $\mathrm{Nicol}$, J. et al. Cooperative organization of inorganicsurfactant and biomimetic assemblies. Science 1995, 267, 1138-1143.

[45] Taguchi, A.; Schuth, F. Ordered mesoporous materials in catalysis. Micropor. Mesopor. Mater. 2005, 77, 1-45.
[46] Tian, B. Z.; Liu, X. Y.; Tu, B.; Yu, C. Z.; Fan, J.; Wang, L. M.; Xie, S. H.; Stucky, G. D.; Zhao, D. Y. Self-adjusted synthesis of ordered stable mesoporous minerals by acidbase pairs. Nat. Mater. 2003, 2, 159-163.

[47] On, D. T.; Desplantier-Giscard, D.; Danumah, C.; Kaliaguine, S. Perspectives in catalytic applications of mesostructured materials. Appl. Catal. A-Gen. 2003, 253, 545-602.

[48] Yue, Y. H.; Gedeon, A.; Bonardet, J. L.; Melosh, N.; D'Espinose, J. B.; Fraissard, J. Direct synthesis of AISBA mesoporous molecular sieves: Characterization and catalytic activities. Chem. Commun. 1999, 1967-1968.

[49] Tuel, A. Modification of mesoporous silicas by incorporation of heteroelements in the framework. Micropor. Mesopor. Mater. 1999, 27, 151-169.

[50] On, D. T.; Joshi, P. N.; Kaliaguine, S. Synthesis, stability and state of boron in boron-substituted MCM-41 mesoporous molecular sieves. J. Phys. Chem. 1996, 100, 6743-6748.

[51] Fricke, R.; Kosslick, H.; Lischke, G.; Richter, M. Incorporation of gallium into zeolites: Syntheses, properties and catalytic application. Chem. Rev. 2000, 100, 2303-2405.

[52] Kosslick, H.; Lischke, G.; Landmesser, H.; Parlitz, B.; Storek, W.; Fricke, R. Acidity and catalytic behavior of substituted MCM-48. J. Catal. 1998, 176, 102-114.

[53] Kosslick, H.; Lischke, G.; Walther, G.; Storek, W.; Martin, A.; Fricke, R. Physico-chemical and catalytic properties of Al-, Ga- and Fe-substituted mesoporous materials related to MCM-41. Micropor. Mater. 1997, 9, 13-33.

[54] Mokaya, R.; Jones, W. Post-synthesis grafting of Al onto MCM-41. Chem. Commun. 1997, 2185-2186.

[55] O’Neil, A. S.; Mokaya, R.; Poliakoff, M. Supercritical fluid-mediated alumination of mesoporous silica and its beneficial effect on hydrothermal stability. J. Am Chem. Soc. 2002, 124, 10636-10637.

[56] Corma, A.; Fornes, V.; Navarro, M. T.; Perez-Pariente, J. Acidity and stability of MCM-41 crystalline aluminosilicalites. J. Catal. 1994, 148, 569-574.

[57] Gedeon, A.; Lassoued, A.; Bonardet, J. L.; Fraissard, J. Surface acidity diagnosis and catalytic activity of AISBA materials obtained by direct synthesis. Micropor. Mesopor. Mater. 2001, 44-45, 801-806.

[58] On, D. T.; Kaliaguine, S. Ultrastable and highly acidic, zeolite-coated mesoporous aluminosilicates. Angew. Chem. Int. Edit. 2002, 41, 1036-1040. 
[59] Huang, L. M.; Guo, W. P.; Deng, P.; Xue, Z. Y.; Li, Q. Z. Investigation of synthesizing MCM-41/ZSM-5 composites. J. Phys. Chem. B 2000, 104, 2817-2823.

[60] Jacobsen, C. J. H.; Madsen, C.; Houzvicka, J.; Schmidt, I.; Carlsson, A. Mesoporous zeolite single crystals. J. Am. Chem. Soc. 2000, 122, 7116-7117.

[61] Janssen, A. H.; Schmidt, I.; Jacobsen, C. J. H.; Koster, A. J.; de Jong, K. P. Exploratory study of mesopore templating with carbon during zeolite synthesis. Micropor. Mesopor. Mater. 2003, 65, 59-75.

[62] Xiao, F. S.; Wang, L. F.; Yin, C. Y. ; Lin, K. F. ; Di, Y. ; Li, J. X. ; Xu, R. R. ; Su, D. S. ; Schlogl, R. ; Yokoi, T.; Tatsumi, T. Catalytic properties of hierarchical mesoporous zeolites templated with a mixture of small organic ammonium salts and mesoscale cationic polymers. Angew. Chem. -Int. Edit. 2006, 45, 3090-3093.

[63] Choi, M.; Cho, H. S.; Srivastava, R.; Venkatesan, C.; Choi, D. H.; Ryoo, R. Amphiphilic organosilane-directed synthesis of crystalline zeolite with tunable mesoporosity. Nat. Mater. 2006, 5, 718-723.

[64] Christensen, C. H.; Johannsen, K.; Schmidt, I.; Christensen, C. H. Catalytic benzene alkylation over mesoporous zeolite single crystals: Improving activity and selectivity with a new family of porous materials. J. Am. Chem. Soc. 2003, 125, 13370-13371.

[65] Tanev, P. T.; Chibwe, M.; Pinnavaia, T. J. Titaniumcontaining mesoporous molecular-sieves for catalyticoxidation of aromatic-compounds. Nature 1994, 368, 321-323.

[66] Zhang, W. H.; Froba, M.; Wang, J. L.; Tanev, P. T.; Wong, J.; Pinnavaia, T. J. Mesoporous titanosilicate molecular sieves prepared at ambient temperature by electrostatic $\left(\mathrm{S}^{+} \mathrm{I}^{-}, \mathrm{S}^{+} \mathrm{X}^{-} \mathrm{I}^{+}\right)$and neutral $\left(\mathrm{S}^{0} \mathrm{I}^{0}\right)$ assembly pathways: A comparison of physical properties and catalytic activity for peroxide oxidations. J. Am. Chem. Soc. 1996, 118, 9164-9171.

[67] Corma, A.; Navarro, M. T.; Perez-Pariente, J.; Sanchez, F. Zeolites and Related Microporous Materials: State of the Art. Stud. Surf. Sci. Catal. 1994, 84, 69-75.

[68] Tozzola, G.; Mantegazza, M. A.; Ranghino, G.; Petrini, G.; Bordiga, S.; Ricchiardi, G.; Lamberti, C.; Zulian, R.; Zecchina, A. On the structure of the active site of Ti-silicalite in reactions with hydrogen peroxide: $A$ vibrational and computational study. J. Catal. 1998, 179, 64-71.

[69] Bordiga, S.; Bonino, F.; Damin, A.; Lamberti, C. Reactivity of Ti(IV) species hosted in TS-1 towards $\mathrm{H}_{2} \mathrm{O}_{2}-\mathrm{H}_{2} \mathrm{O}$ solutions investigated by ab initio cluster and periodic approaches combined with experimental XANES and EXAFS data: A review and new highlights. Phys. Chem. Chem. Phys. 2007, 9, 4854-4878.

[70] Chen, H.; Dai, W. L.; Deng, J. F.; Fan, K. N. Novel heterogeneous W-doped MCM-41 catalyst for highly selective oxidation of cyclopentene to glutaraldehyde by aqueous $\mathrm{H}_{2} \mathrm{O}_{2}$. Catal. Lett. 2002, 81, 131-136.

[71] Yang, X. L.; Dai, W. L.; Gao, R. H.; Chen, H.; Li, H. X.; Cao, Y.; Fan, K. N. Synthesis, characterization and catalytic application of mesoporous W-MCM-48 for the selective oxidation of cyclopentene to glutaraldehyde. J. Mol. Catal. A-Chem. 2005, 241, 205-214.

[72] Reddy, K. M.; Moudrakovski, I.; Sayari, A. Synthesis of mesoporous vanadium silicate molecular-sieves. J. Chem. Soc. Chem. Commun. 1994, 1059-1060.

[73] Reddy, J. S.; Sayari, A. Room-temperature synthesis of a highly-active vanadium-containing mesoporous molecular-sieve, V-HMS. J. Chem. Soc. Chem. Commun. 1995, 2231-2232.

[74] Schlogl, R.; Abd Hamid, S. B. Nanocatalysis: Mature science revisited or something really new? Angew. Chem. Int. Edit. 2004, 43, 1628-1637.

[75] Garcia, C.; Zhang, Y. M.; DiSalvo, F.; Wiesner, U. Mesoporous aluminosilicate materials with superparamagnetic $y-\mathrm{Fe}_{2} \mathrm{O}_{3}$ particles embedded in the walls. Angew. Chem. Int. Edit. 2003, 42, 1526-1530.

[76] Dong, W. Y.; Sun, Y. J.; Lee, C. W.; Hua, W. M.; Lu, X. C.; Shi, Y. F.; Zhang, S. C.; Chen, J. M.; Zhao, D. Y. Controllable and repeatable synthesis of thermally stable anatase nanocrystal-silica composites with highly ordered hexagonal mesostructures. J. Am. Chem. Soc. 2007, 129, 13894-13904.

[77] Corma, A.; Chane-Ching, J. Y.; Airiau, M.; Martinez, C. Synthesis and catalytic properties of thermally and hydrothermally stable, high-surface-area $\mathrm{SiO}_{2}-\mathrm{CeO}_{2}$ mesostructured composite materials and their application for the removal of sulfur compounds from gasoline. J. Catal. 2004, 224, 441-448.

[78] Hu, J. C.; Chen, L. F.; Zhu, K. K.; Suchopar, A.; Richards, R. Aerobic oxidation of alcohols catalyzed by gold nanoparticles confined in the walls of mesoporous silica. Catal. Today 2007, 122, 277-283.

[79] Wolf, A.; Schuth, F. A systematic study of the synthesis conditions for the preparation of highly active gold 
catalysts. Appl. Catal. A-Chem 2002, 226, 1-13.

[80] Zhu, K. K.; Hu, J. C.; Richards, R. Aerobic oxidation of cyclohexane by gold nanoparticles immobilized upon mesoporous silica. Catal. Lett. 2005, 100, 195-199.

[81] Song, H.; Rioux, R. M.; Hoefelmeyer, J. D.; Komor, R.; Niesz, K.; Grass, M.; Yang, P. D.; Somorjai, G. A. Hydrothermal growth of mesoporous SBA-15 silica in the presence of PVP-stabilized Pt nanoparticles: Synthesis, characterization, and catalytic properties. J. Am. Chem. Soc. 2006, 128, 3027-3037.

[82] Schuth, F. Non-siliceous mesostructured and mesoporous materials. Chem. Mater. 2001, 13, 3184-3195.

[83] Yang, P. D.; Zhao, D. Y.; Margolese, D. I.; Chmelka, B. F.; Stucky, G. D. Block copolymer templating syntheses of mesoporous metal oxides with large ordering lengths and semicrystalline framework. Chem. Mater. 1999, 11, 2813-2826.

[84] Yuan, Q.; Yin, A. X.; Luo, C.; Sun, L. D.; Zhang, Y. W.; Duan, W. T.; Liu, H. C.; Yan, C. H. Facile synthesis for ordered mesoporous $y$-aluminas with high thermal stability. J. Am. Chem. Soc. 2008, 130, 3465-3472.

[85] Yoshitake, H.; Tatsumi, T. Vanadium oxide incorporated into mesoporous titania with a BET surface area above $1000 \mathrm{~m}^{2} / \mathrm{g}$ : Preparation, spectroscopic characterization, and catalytic oxidation. Chem. Mater. 2003, 15, 16951702.

[86] Kapoor, M. P.; Ichihashi, Y.; Kuraoka, K.; Matsumura, Y. Catalytic methanol decomposition over palladium deposited on thermally stable mesoporous titanium oxide. J. Mol. Catal. A-Chem. 2003, 198, 303-308.

[87] Serre, C.; Auroux, A.; Gervasini, A.; Hervieu, M.; Ferey, G. Hexagonal and cubic thermally stable mesoporous tin(IV) phosphates with acidic and catalytic properties. Angew. Chem. -Int. Edit. 2002, 41, 1594-1597.

[88] Bhaumik, A.; Inagaki, S. Mesoporous titanium phosphate molecular sieves with ion-exchange capacity. J. Am. Chem. Soc. 2001, 123, 691-696.

[89] Onaka, M.; Oikawa, T. Olefin metathesis over mesoporous alumina-supported rhenium oxide catalyst. Chem. Lett. 2002, 850-851.

[90] Velu, S.; Kapoor, M. P.; Inagaki, S.; Suzuki, K. Vapor phase hydrogenation of phenol over palladium supported on mesoporous $\mathrm{CeO}_{2}$ and $\mathrm{ZrO}_{2}$. Appl. Catal. A-Chem 2003, 245, 317-331.

[91] Farrusseng, D.; Schlichte, K.; Spliethoff, B.; Wingen, A.; Kaskel, S.; Bradley, J. S.; Schuth, F. Pore-size engineering of silicon imido nitride for catalytic applications. Angew. Chem. Int. Edit. 2001, 40, 4204-4207.

[92] Wang, D. H.; Choi, D. W.; Yang, Z. G.; Viswanathan, V. V.; Nie, Z. M.; Wang, C. M.; Song, Y. J.; Zhang, J. G.; Liu, J. Synthesis and Li-ion insertion properties of highly crystalline mesoporous rutile $\mathrm{TiO}_{2}$. Chem. Mater. 2008, 20, 3435-3442.

[93] Wang, D. H.; Ma, Z.; Dai, S.; Liu, J.; Nie, Z. M.; Engelhard, M. H.; Huo, Q. S.; Wang, C. M.; Kou, R. Lowtemperature synthesis of tunable mesoporous crystalline transition metal oxides and applications as Au catalyst supports. J. Phys. Chem. C 2008, 112, 13499-13509.

[94] Wong, M. S.; Jeng, E. S.; Ying, J. Y. Supramolecular templating of thermally stable crystalline mesoporous metal oxides using nanoparticulate precursors. Nano Lett. 2001, 1, 637-642.

[95] Chane-Ching, J. Y.; Cobo, F.; Aubert, D.; Harvey, H. G.; Airiau, M.; Corma, A. A general method for the synthesis of nanostructured large-surface-area materials through the self-assembly of functionalized nanoparticles. ChemEur. J. 2005, 11, 979-987.

[96] Corma, A.; Atienzar, P.; Garcia, H.; Chane-Ching, J. Y. Hierarchically mesostructured doped $\mathrm{CeO}_{2}$ with potential for solar-cell use. Nat. Mater. 2004, 3, 394-397.

[97] Corma, A.; Domine, M. E. Gold supported on a mesoporous $\mathrm{CeO}_{2}$ matrix as an efficient catalyst in the selective aerobic oxidation of aldehydes in the liquid phase. Chem. Commun. 2005, 4042-4044.

[98] Pinnavaia, T. J. Intercalated clay catalysts. Science 1983, 220, 365-371.

[99] Wang, L. Z.; Ebina, Y.; Takada, K.; Kurashima, K.; Sasaki, T. A new mesoporous manganese oxide pillared with double layers of alumina. Adv. Mater. 2004, 16, 14121416.

[100] Kim, T. W.; Hwang, S. J.; Jhung, S. H.; Chang, J. S.; Park, H.; Choi, W.; Choy, J. H. Bifunctional heterogeneous catalysts for selective epoxidation and visible light driven photolysis: Nickel oxide-containing porous nanocomposite. Adv. Mater. 2008, 20, 539542.

[101] Ma, Y.; Suib, S. L.; Ressler, T.; Wong, J.; Lovallo, M.; Tsapatsis, M. Synthesis of porous $\mathrm{CrO}_{x}$ pillared octahedral layered manganese oxide materials. Chem. Mater. 1999, 11, 3545-3554.

[102] Yamanaka, S.; Kunii, K.; Xu, Z. L. Preparation and adsorption properties of microporous manganese 
titanate pillared with silica. Chem. Mater. 1998, 10, 1931-1936.

[103] Wong, S. T.; Cheng, S. Synthesis and characterization of pillared buserite. Inorg. Chem. 1992, 31, 1165-1172.

[104] Sasaki, T.; Watanabe, M. Osmotic swelling to exfoliation. Exceptionally high degrees of hydration of a layered titanate. J. Am. Chem. Soc. 1998, 120, 46824689.

[105] Liu, Z. H; Ooi, K.; Kanoh, H.; Tang, W. P.; Tomida, T. Swelling and delamination behaviors of birnessitetype manganese oxide by intercalation of tetraalkylammonium ions. Langmuir 2000, 16, 41544164.

[106] Hata, H.; Kobayashi, Y.; Salama, M.; Malek, R.; Mallouk, T. E. pH-dependent intercalation of gold nanoparticles into a synthetic fluoromica modified with poly(allylamine). Chem. Mater. 2007, 19, 6588-6596.

[107] Hata, H.; Kubo, S.; Kobayashi, Y.; Mallouk, T. E. Intercalation of well-dispersed gold nanoparticles into layered oxide nanosheets through intercalation of a polyamine. J. Am. Chem. Soc. 2007, 129, 3064-3065.

[108] Liu, Y.; Zhang, W. Z.; Pinnavaia, T. J. Steam-stable aluminosilicate mesostructures assembled from zeolite type $\mathrm{Y}$ seeds. J. Am. Chem. Soc. 2000, 122, 87918792.

[109] Liu, Y.; Zhang, W. Z.; Pinnavaia, T. J. Steam-stable MSU-S aluminosilicate mesostructures assembled from zeolite ZSM-5 and zeolite beta seeds. Angew. Chem. Int. Edit. 2001, 40, 1255-1258.

[110] Zhang, Z. T.; Han, Y.; Zhu, L.; Wang, R. W.; Yu, Y.; Qiu, S. L.; Zhao, D. Y.; Xiao, F. S. Strongly acidic and high-temperature hydrothermally stable mesoporous aluminosilicates with ordered hexagonal structure. Angew. Chem. Int. Edit. 2001, 40, 1258-1262.

[111] Liu, J.; Shin, Y.; Nie, Z. M.; Chang, J. H.; Wang, L. Q.; Fryxell, G. E.; Samuels, W. D.; Exarhos, G. J. Molecular assembly in ordered mesoporosity: A new class of highly functional nanoscale materials. J. Phys. Chem. A 2000, 104, 8328-8339.

[112] Margelefsky, E. L.; Zeidan, R. K.; Dufaud, V.; Davis, M. E. Organized surface functional groups: Cooperative catalysis via thiol/sulfonic acid pairing. J. Am. Chem. Soc. 2007, 129, 13691-13697.

[113] Dufaud, V.; Davis, M. E. Design of heterogeneous catalysts via multiple active site positioning in organic -inorganic hybrid materials. J. Am. Chem. Soc. 2003,
125, 9403-9413.

[114] Li, C.; Zhang, H. D.; Jiang, D. M.; Yang, Q. H. Chiral catalysis in nanopores of mesoporous materials. Chem. Commun. 2007, 547-558.

[115] Raja, R.; Thomas, J. M.; Jones, M. D.; Johnson, B. F. G.; Vaughan, D. E. W. Constraining asymmetric organometallic catalysts within mesoporous supports boosts their enantioselectivity. J. Am. Chem. Soc. 2003, 125, 14982-14983.

[116] Kaleta, W.; Nowinska, K. Immobilisation of heteropoly anions in Si-MCM-41 channels by means of chemical bonding to aminosilane groups. Chem. Commun. 2001, 535-536.

[117] Chen, L. F.; Zhu, K.; Bi, L. H.; Suchopar, A.; Reicke, M.; Mathys, G.; Jaensch, H.; Kortz, U.; Richards, R. M. Solvent-free aerobic oxidation of $n$-alkane by iron(III)substituted polyoxotungstates immobilized on SBA-15 Inorg. Chem. 2007, 46, 8457-8459.

[118] Pope, M. T.; Muller, A. Polyoxometalate chemistryAn old field with new dimensions in several disciplines. Angew. Chem. Int. Ed. Engl. 1991, 30, 34-48.

[119] Pope, M. T. Heteropoly and Isopoly Oxometalates; Springer-Verlag: Berlin, 1983.

[120]Volkmer, D.; Du Chesne, A.; Kurth, D. G.; Schnablegger, H.; Lehmann, P.; Koop, M. J.; Muller, A. Toward nanodevices: Synthesis and characterization of the nanoporous surfactant-encapsulated Keplerate $(\mathrm{DODA})_{40}\left(\mathrm{NH}_{4}\right)_{2}\left[\left(\mathrm{H}_{2} \mathrm{O}\right)_{n} \subset \mathrm{Mo}_{132} \mathrm{O}_{372}\left(\mathrm{CH}_{3} \mathrm{COO}\right)_{30}\left(\mathrm{H}_{2} \mathrm{O}\right)_{72}\right]$ J. Am. Chem. Soc. 2000, 122, 1995-1998.

[121] Fan, D. W.; Jia, X. F.; Tang, P. Q.; Hao, J. C.; Liu, T. B. Self-patterning of hydrophobic materials into highly ordered honeycomb nanostructures at the air/water interface. Angew. Chem. Int. Edit. 2007, 46, 33423345.

[122] Neumann, R. Polyoxometallate complexes in organic oxidation chemistry. Prog. Inorg. Chem. 1998; 47, 317370 .

[123] Kozhevnikov, I. V. Catalysis by heteropoly acids and multicomponent polyoxometalates in liquid-phase reactions. Chem. Rev. 1998, 98, 171-198.

[124] Hill, C. L.; Prossermccartha, C. M. Homogeneous catalysis by transition-metal oxygen anion clusters. Coord. Chem. Rev. 1995, 143, 407-455.

[125] Mizuno, N.; Misono, M. Heterogenous catalysis. Chem. Rev. 1998, 98, 199-217.

[126] Mizuno, N.; Yamaguchi, K.; Kamata, K. Epoxidation 
of olefins with hydrogen peroxide catalyzed by polyoxometalates. Coord. Chem. Rev. 2005, 249, 1944 $-1956$.

[127] Liu, Y. Y.; Koyano, G.; Na, K.; Misono, M. Isomerizations of $n$-pentane and $n$-hexane over cesium hydrogen salt of 12-tungstophosphoric acid promoted by platinum. Appl. Catal. A-Gen. 1998, 166, L263-L265.

[128] Misono, M. Heterogeneous catalysis by heteropoly compounds of molybdenum and tungsten. Catal. Rev. -Sci. Eng. 1987, 29, 269-321.

[129] Yamada, T.; Yoshinaga, Y.; Okuhara, T. Synthesis and characterization of an ultramicroporous cesium hydrogen salt of 12 -tungstophosphoric acid, $\mathrm{Cs}_{2.1} \mathrm{H}_{0.9} \mathrm{PW}_{12} \mathrm{O}_{40}$. Bull. Chem. Soc. Jpn. 1998, 71, 2727-2734.

[130] Rhule, J. T.; Neiwert, W. A.; Hardcastle, K. I.; Do, B. T.; Hill, C. L. $\mathrm{Ag}_{5} \mathrm{PV}_{2} \mathrm{Mo}_{10} \mathrm{O}_{40}$, a heterogeneous catalyst for air-based selective oxidation at ambient temperature. J. Am. Chem. Soc. 2001, 123, 12101-12102.

[131] Yamaguchi, K.; Mizuno, N. Heterogeneously catalyzed liquid-phase oxidation of alkanes and alcohols with molecular oxygen. New J. Chem. 2002, 26, 972-974.

[132] Xi, Z. W.; Zhou, N.; Sun, Y.; Li, K. L. Reaction-controlled phase-transfer catalysis for propylene epoxidation to propylene oxide. Science 2001, 292, 1139-1141.

[133] Xi, Z. W.; Wang, H. P.; Sun, Y.; Zhou, N.; Cao, G. Y.; Li, M. Direct epoxidation of olefins catalyzed by heteropolyoxometalates with molecular oxygen and recyclable reductant. J. Mol. Catal. A-Chem. 2001, 168, 299-301.

[134] Uchida, S.; Hashimoto, M.; Mizuno, N. A breathing ionic crystal displaying selective binding of small alcohols and nitriles: $\mathrm{K}_{3}\left[\mathrm{Cr}_{3} \mathrm{O}(\mathrm{OOCH})_{6}\left(\mathrm{H}_{2} \mathrm{O}\right)_{3}\right]$ [alpha$\left.\mathrm{SiW}_{12} \mathrm{O}_{40}\right] \cdot 16 \mathrm{H}_{2} \mathrm{O}$. Angew. Chem. Int. Edit. 2002, 41, 2814-2817.

[135] Uchida, S.; Mizuno, N. Zeotype ionic crystal of $\mathrm{CS}_{5}\left[\mathrm{Cr}_{3} \mathrm{O}(\mathrm{OOCH})_{6}\left(\mathrm{H}_{2} \mathrm{O}\right)_{3}\right]\left[\left(\right.\right.$ alpha- $\left.\mathrm{CoW}_{12} \mathrm{O}_{40}\right] \cdot 7.5 \mathrm{H}_{2} \mathrm{O}$ with shape-selective adsorption of water. J. Am. Chem. Soc. 2004, 126, 1602-1603.

[136] Uchida, S.; Mizuno, N. Unique guest-inclusion properties of a breathing ionic crystal of $\mathrm{K}_{3}\left[\mathrm{Cr}_{3} \mathrm{O}(\mathrm{OOCH})_{6}\left(\mathrm{H}_{2} \mathrm{O}\right)_{3}\right]\left[\right.$ alpha-SiW $\left.{ }_{12} \mathrm{O}_{40}\right] \cdot 16 \mathrm{H}_{2} \mathrm{O}$. Chem.Eur. J. 2003, 9, 5850-5857.

[137] Uchida, S.; Kawamoto, R.; Mizuno, N. Recognition of small polar molecules with an ionic crystal of alphaKeggin-type polyoxometalate with a macrocation.
Inorg. Chem. 2006, 45, 5136-5144.

[138] Kawamoto, R.; Uchida, S.; Mizuno, N. Amphiphilic guest sorption of $\mathrm{K}_{2}\left[\mathrm{Cr}_{3} \mathrm{O}\left(\mathrm{OOCC}{ }_{2} \mathrm{H}_{5}\right)_{6}\left(\mathrm{H}_{2} \mathrm{O}\right)_{3}\right]_{2}$ [alpha$\mathrm{SiW}_{12} \mathrm{O}_{40}$ ] ionic crystal. J. Am. Chem. Soc. 2005, 127, 10560-10567.

[139] Uchida, S.; Kawamoto, R.; Akatsuka, T.; Hikichi, S.; Mizuno, N. Structures and sorption properties of ionic crystals of macrocation-Dawson-type polyoxometalates with different charges. Chem. Mater. 2005, 17, 13671375.

[140] Uchida, S.; Mizuno, N. Design and syntheses of nano-structured ionic crystals with selective sorption properties. Coord. Chem. Rev. 2007, 251, 2537-2546.

[141] Okun, N. M.; Anderson, T. M.; Hill, C. L. [(FeIII $\left.\left.\left(\mathrm{OH}_{2}\right)_{2}\right)_{3}\left(\mathrm{~A} \text {-alpha- } \mathrm{PW}_{9} \mathrm{O}_{34}\right)_{2}\right]^{9-}$ on cationic silica nanoparticles, a new type of material and efficient heterogeneous catalyst for aerobic oxidations. J. Am. Chem. Soc. 2003, 125, 3194-3195.

[142] Okun, N. M.; Ritorto, M. D.; Anderson, T. M.; Apkarian, R. P.; Hill, C. L. Polyoxometalates on cationic silica nanoparticles. Physicochemical properties of an electrostatically bound multi-iron catalyst. Chem. Mater. 2004, 16, 2551-2558.

[143] Okun, N. M.; Anderson, T. M.; Hill, C. L. Polyoxometalates on cationic silica-Highly selective and efficient $\mathrm{O}_{2}$ /air-based oxidation of 2-chloroethyl ethyl sulfide at ambient temperature. J. Mol. Catal. A-Chem. 2003, 197, 283-290.

[144] Kwon, T.; Tsigdinos, G. A.; Pinnavaia, T. J. Pillaring of layered double hydroxides (LDHs) by polyoxometalate anions. J. Am. Chem. Soc. 1988, 110, 3653-3654.

[145] Rives, V.; Ulibarri, M. A. Layered double hydroxides (LDH) intercalated with metal coordination compounds and oxometalates. Coord. Chem. Rev. 1999, 181, 61-120.

[146] Liu, P.; Wang, H.; Feng, Z. C.; Ying, P. L.; Li, C. Direct immobilization of self-assembled polyoxometalate catalyst in layered double hydroxide for heterogeneous epoxidation of olefins. J. Catal. 2008, 256, 345-348.

[147] Centi, G.; Perathoner, S. Catalysis by layered materials: A review. Micropor. Mesopor. Mat. 2008, 107, 3-15.

[148] Jana, S. K.; Kubota, Y.; Tatsumi, T. Cobalt-substituted polyoxometalate pillared hydrotalcite: Synthesis and catalysis in liquid-phase oxidation of cyclohexanol with molecular oxygen. J. Catal. 2008, 255, 40-47.

[149] Liu, Y. Y.; Murata, K.; Hanaoka, T.; Inaba, M.; Sakanishi, $K$. Syntheses of new peroxo-polyoxometalates 
intercalated layered double hydroxides for propene epoxidation by molecular oxygen in methanol. J. Catal. 2007, 248, 277-287.

[150] Kwon, T.; Pinnavaia, T. J. Synthesis and properties of anionic clays pillared by $\left[\mathrm{XM}_{12} \mathrm{O}_{40}\right]_{n}$ - Keggin ions. J. Mol. Catal. 1992, 74, 23-33.

[151] Kwon, T.; Pinnavaia, T. J. Pillaring of a layered double hydroxide by polyoxometalates with Keggin-ion structures. Chem. Mater. 1989, 1, 381-383.

[152] Tomalia, D. A.; Naylor, A. M.; Goddard, W. A. Starburst dendrimers-molecular-level control of size, shape, surface-chemistry, topology, and flexibility from atoms to macroscopic matter. Angew. Chem. Int. Edit. Engl. 1990, 29, 138-175.

[153] Astruc, D.; Chardac, F. Dendritic catalysts and dendrimers in catalysis. Chem. Rev. 2001, 101, 29913023.

[154] Twyman, L. J.; King, A. S. H.; Martin, I. K. Catalysis inside dendrimers. Chem. Soc. Rev. 2002, 31, 69-82.

[155] Scott, R. W. J.; Wilson, O. M.; Oh, S. K.; Kenik, E. A.; Crooks, R. M. Bimetallic palladium-gold dendrimerencapsulated catalysts. J. Am. Chem. Soc. 2004, 126, 15583-15591.

[156] Brunner, H. Dendrizymes-expanded ligands for enantioselective catalysis. J. Organomet. Chem. 1995, 500, 39-46.

[157] Niu, Y. H.; Yeung, L. K.; Crooks, R. M. Size-selective hydrogenation of olefins by dendrimer-encapsulated palladium nanoparticles. J. Am. Chem. Soc. 2001, 123, 6840-6846.

[158] Balogh, L.; Tomalia, D. A. Poly(amidoamine) dendrimertemplated nanocomposites. 1. Synthesis of zerovalent copper nanoclusters. J. Am. Chem. Soc. 1998, 120, 7355-7356.

[159] Scott, R. W. J.; Wilson, O. M.; Crooks, R. M. Synthesis, characterization, and applications of dendrimerencapsulated nanoparticles. J. Phys. Chem. B 2005, 109, 692-704.

[160] Wilson, O. M.; Scott, R. W. J.; Garcia-Martinez, J. C.; Crooks, R. M. Synthesis, characterization, and structure-selective extraction of 1-3-nm diameter AuAg dendrimer-encapsulated bimetallic nanoparticles. J. Am. Chem. Soc. 2005, 127, 1015-1024.

[161] Wang, G. Y.; Liu, X. Y.; Zhao, G. Synthesis of dendrimer-supported prolinols and their application in enantioselective reduction of ketones. Synlett 2006,
1150-1154.

[162] Chung, Y. M.; Rhee, H. K. Design of silica-supported dendritic chiral catalysts for the improvement of enantio selective addition of diethylzinc to benzaldehyde. Catal. Lett. 2002, 82, 249-253.

[163] Chung, Y. M.; Rhee, H. K. Dendritic chiral auxiliaries on silica: A new heterogeneous catalyst for enantioselective addition of diethylzinc to benzaldehyde. Chem. Commun. 2002, 238-239.

[164] Scott, R. W. J.; Sivadinarayana, C.; Wilson, O. M.; Yan, Z.; Goodman, D. W.; Crooks, R. M. Titania-supported $\mathrm{PdAu}$ bimetallic catalysts prepared from dendrimerencapsulated nanoparticle precursors. J. Am. Chem. Soc. 2005, 127, 1380-1381.

[165]Zeng, H. D.; Newkome, G. R.; Hill, C. L. Poly(polyoxometalate) dendrimers: Molecular prototypes of new catalytic materials. Angew. Chem. Int. Edit. 2000, 39, 1771-1774.

[166] Kasuga, T.; Hiramatsu, M.; Hoson, A.; Sekino, T.; Niihara, K. Formation of titanium oxide nanotube. Langmuir 1998, 14, 3160-3163.

[167] Sun, X. M.; Li, Y. D. Synthesis and characterization of ion-exchangeable titanate nanotubes. Chem. -Eur. J. 2003, 9, 2229-2238.

[167] Bavykin, D. V.; Lapkin, A. A.; Plucinski, P. K.; Friedrich, J. M.; Walsh, F. C. $\mathrm{TiO}_{2}$ nanotube-supported ruthenium(III) hydrated oxide: A highly active catalyst for selective oxidation of alcohols by oxygen. J. Catal. 2005, 235, 10 -17 .

[169] Bavykin, D. V.; Lapkin, A. A.; Plucinski, P. K.; TorrenteMurciano, L.; Friedrich, J. M.; Walsh, F. C. Deposition of Pt, Pd, Ru, and $\mathrm{Au}$ on the surfaces of titanate nanotubes. Top. Catal. 2006, 39, 151-160.

[170] Xu, J. C.; Lu, M.; Guo, X. Y.; Li, H. L. Zinc ions surface-doped titanium dioxide nanotubes and its photocatalysis activity for degradation of methyl orange in water. J. Mol. Catal. A-Chem. 2005, 226, 123-127.

[171] Huang, P. X.; Wu, F.; Zhu, B. L.; Gao, X. P.; Zhu, H. Y.; Yan, T. Y.; Huang, W. P.; Wu, S. H.; Song, D. Y. $\mathrm{CeO}_{2}$ nanorods and gold nanocrystals supported on $\mathrm{CeO}_{2}$ nanorods as catalyst. J. Phys. Chem. B 2005, 109, 19169-19174.

[172] Wu, J. J.; Tseng, C. H. Photocatalytic properties of ncAu/ZnO nanorod composites. Appl. Catal. B-Environ. 2006, 66, 51-57.

[173] Tasker, P. W. The stability of ionic-crystal surfaces. J. 
Phys. C-Solid State Phys. 1979, 12, 4977-4984.

[174] Arita, R.; Tanida, Y.; Entani, S.; Kiguchi, M.; Saiki, $\mathrm{K}$.; Aoki, H. Polar surface engineering in ultrathin $\mathrm{MgO}(111) / \mathrm{Ag}(111)$ : Possibility of a metal-insulator transition and magnetism. Phys. Rev. B 2004, 69, 235423-235423.

[175] Plass, R.; Egan, K.; Collazo-Davila, C.; Grozea, D.; Landree, E.; Marks, L. D.; Gajdardziska-Josifovska, M. Cyclic ozone identified in magnesium oxide (111) surface reconstructions. Phys. Rev. Lett. 1998, 81, 4891 $-4894$.

[176] Itoh, H.; Utamapanya, S.; Stark, J. V.; Klabunde, K. J.; Schlup, J. R. Nanoscale metal-oxide particles as chemical reagents-intrinsic effects of particle-size on hydroxyl content and on reactivity and acid-base properties of ultrafine magnesium oxide. Chem. Mater. 1993, 5, 7177.

[177] Stankic, S.; Muller, M.; Diwald, O.; Sterrer, M.; Knozinger, E.; Bernardi, J. Size-dependent optical properties of $\mathrm{MgO}$ nanocubes. Angew. Chem. Int. Edit. 2005, 44, 4917-4920.

[178] Zhu, K. K.; Hu, J. C.; Kubel, C.; Richards, R. Efficient preparation and catalytic activity of $\mathrm{MgO}(111)$ nanosheets. Angew. Chem. Int. Edit. 2006, 45, 72777281.

[179] Hu, J. C.; Zhu, K.; Chen, L. F.; Kubel, C.; Richards, R. $\mathrm{MgO}(111)$ nanosheets with unusual surface activity. J. Phys. Chem. C 2007, 111, 12038-12044.

[180] Niederberger, M.; Garnweitner, G.; Pinna, N.; Antonietti, M. Nonaqueous and halide-free route to crystalline $\mathrm{BaTiO}_{3}, \mathrm{SrTiO}_{3}$, and $(\mathrm{Ba}, \mathrm{Sr}) \mathrm{TiO}_{3}$ nanoparticles via a mechanism involving $\mathrm{C}-\mathrm{C}$ bond formation. J. Am. Chem. Soc. 2004, 126, 9120-9126.

[181] Niederberger, M.; Bard, M. H.; Stucky, G. D. Benzyl alcohol and transition metal chlorides as a versatile reaction system for the nonaqueous and lowtemperature synthesis of crystalline nano-objects with controlled dimensionality. J. Am. Chem. Soc. 2002, 124, 13642-13643.

[182] Hu, J. C.; Zhu, K. K.; Chen, L. F.; Yang, H. J.; Li, Z.; Suchopar, A.; Richards, R. Preparation and surface activity of single-crystalline $\mathrm{NiO}(111)$ nanosheets with hexagonal holes: A semiconductor nanospanner. Adv. Mater. 2008, 20, 267-271. 